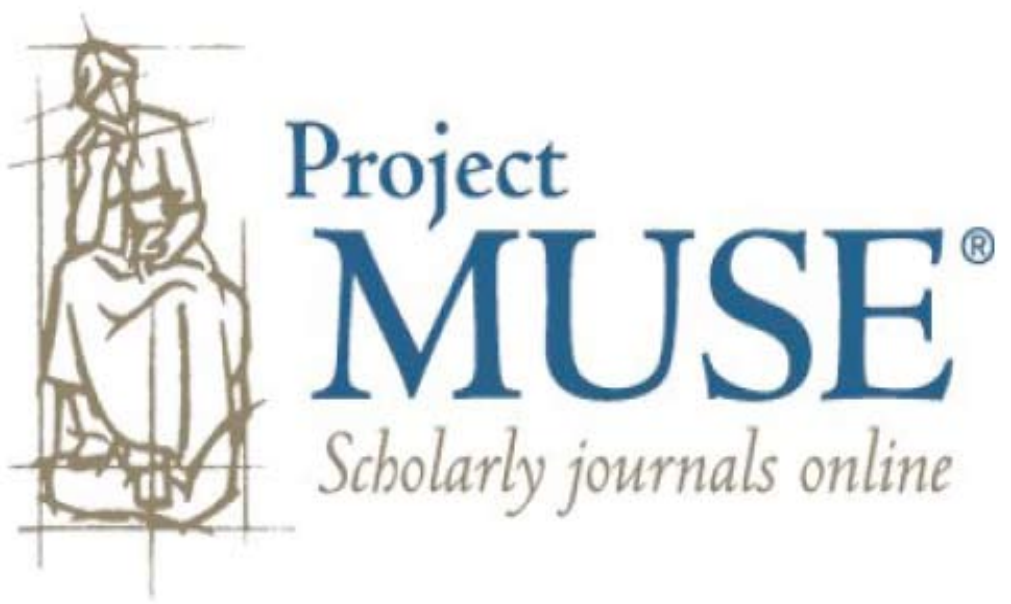




\title{
PRINCIPLES OF EVENT SEGMENTATION IN LANGUAGE: THE CASE OF MOTION EVENTS
}

\author{
JÜRGEN BOHNEMEYER \\ University at \\ Buffalo-SUNY
}

IRAIDE IBARRETXE-

ANTUÑANO

University of Zaragoza

\author{
NichOLAS J. ENFIELD \\ Max Planck Institute for \\ Psycholinguistics \\ Sotaro Kita \\ University of Birmingham
}

\author{
JAMES ESSEGBEY \\ University of Florida
}

FRIEDERIKE LÜPKE

University of London

\section{Felix K. AmeKa \\ Leiden University}

\begin{abstract}
We examine universals and crosslinguistic variation in constraints on event segmentation. Previous typological studies have focused on segmentation into syntactic (Pawley 1987) or intonational units (Givón 1991). We argue that the correlation between such units and semantic/conceptual event representations is language-specific. As an alternative, we introduce the MACRO-EVENT PROPERTY (MEP): a construction has the MEP if it packages event representations such that temporal operators necessarily have scope over all subevents. A case study on the segmentation of motion events into macro-event expressions in eighteen genetically and typologically diverse languages has produced evidence of two types of design principles that impact motion-event segmentation: language-specific lexicalization patterns and universal constraints on form-to-meaning mapping.*
\end{abstract}

1. Toward a semantic typology of motion-event Segmentation. Semantic tyPOLOGY is the comparative study of linguistic categorization-research into how linguistic representations structure a given cognitive domain across languages. Semantic typology begins with the work of the cognitive anthropologists on linguistic categorization in domains such as kinship (e.g. Lounsbury 1969), color (e.g. Berlin \& Kay 1969), and ethnobiological taxonomies (e.g. Berlin et al. 1974). This research responded to claims by structuralists - including, notably, Franz Boas, Edward Sapir, and Benjamin Whorf - to the effect that 'each language, from the point of view of another language, may be arbitrary in its classifications' (Boas 1911:22) and that languages in fact 'differ very widely in their systematization of fundamental concepts' and 'tend to be only loosely equivalent to each other as symbolic devices and are, as a matter of fact, on the whole, incommensurable' (Sapir 1931:578). The early efforts of the cognitive anthropologists were aimed at defeating the view that semantic categories are 'arbitrary' -in the sense of not being constrained by any principles other than purely linguistic ones - and therefore may vary across languages nearly without (nontrivial) bounds. By demonstrating that semantic categories narrowly align with categories of internal cognition, and that there is a core of categorical distinctions that is shared across languages, even in areas where one would expect a great amount of cross-cultural variation,

\footnotetext{
* The research presented here was fully supported by the Max Planck Society. We gratefully acknowledge the collaborators listed in Table 2. Earlier versions of parts of this article were presented at the fourth biannual meeting of the Association for Linguistic Typology (ALTIV) in Santa Barbara, the workshop Event Representation in Language and Cognition at the Max Planck Institute for Psycholinguistics, the symposium on Event Representation in Mind and Language at the University of Oregon, the conference Words and the World at Lehigh University, and at the Amsterdam Center for Language and Communication, the Max Planck Institute for Evolutionary Anthropology, the University at Buffalo, the University of Hawaii at Manoa, and Stanford University. We would like to thank the audiences of these presentations for helpful comments and suggestions. Our special thanks go to the editors of Language and the anonymous referees for highly insightful and constructive criticism!
} 
this research played an important part in the paradigm shift that has brought about the cognitive sciences. More recent studies in semantic typology have corrected the early emphasis on universality somewhat, showing an often surprising amount of diversity in crosslinguistic semantics - specifically in the domain of spatial relations, where one might expect a particularly high amount of cognitive homogeneity (e.g. Levinson et al. 2003, Pederson et al. 1998).

The domain of event representation is ripe for work in semantic typology. Events play a pervasive role in natural language semantics. ${ }^{1}$ At the same time, the relationship between linguistic and internal cognitive event representations is interestingly complex and mutable. Information about an event is usually not mapped onto a single lexical item, but is distributed across phrases, clauses, and larger chunks of discourse. Even within one language the same perceived event can be framed in various different ways. Thus, the utterances in 1 could all serve as descriptions of the same perceived event, and it is easy enough to imagine many more renditions.

(1) a. Sally broke the vase.

b. The vase was broken by Sally.

c. Sally knocked over the vase and it broke.

d. Sally broke the vase by knocking it over.

e. Sally knocked over the vase. It broke.

f. The vase broke. Sally knocked it over.

g. The vase broke because Sally knocked it over.

h. Sally hit the vase. It fell and broke.

Given this intralanguage variability, we may expect a high amount of crosslinguistic variation in event representations as well. We are specifically concerned here with EVENT SEGMENTATION, or the distribution of information about an event across the parts of an utterance. For instance, the breaking event in 1 is packaged in a single clause in $1 \mathrm{a}-\mathrm{b}$, segmented across two clauses in $1 \mathrm{c}-\mathrm{g}$, and segmented across three clauses in 1h. Do all languages offer the same range of possible segmentations for the same extralinguistic or perceived event?

In the case of color terms, kinship terminology, botanical or zoological nomenclature, and spatial relations, semantic typology is primarily or exclusively concerned with lexical semantics. The typology of event segmentation has a lexical component as well: to what extent and in what respects do languages vary in the lexical labels (most commonly, verbs) they provide for event categories? Events are not generally encoded by verbs alone, however, but by productive grammatical constructions, such as verb phrases or clauses. Hence, semantic categories of event representation cannot simply be inventoried. The typology of event segmentation must address the constraints that different languages impose on the segmentation of dynamic stimuli into semantic event categories. It is argued below that such constraints derive partly from 'lexicalization patterns' (in the parlance of Talmy 1985) and partly from the availability of syntactic constructions with certain properties.

We focus on motion as a subdomain of event representation. ${ }^{2}$ We choose this subdomain because of its presumed universality and basicness. According to Miller and

\footnotetext{
${ }^{1}$ See Parsons 1990 and Pianesi \& Varzi 2000 for overviews. We lay out our assumptions about linguistic event representations briefly in $\S 3$. In a nutshell, we assume that events are represented in language and cognition as time-bound entities individuated by their temporal boundaries, the temporal and causal relations they maintain with other events, and the identity of their participants.

${ }^{2}$ The approach we present here-using the macro-event property as a criterion of event segmentation—can and has been applied to other domains of event encoding. Bohnemeyer, Enfield, Essegbey, and Kita (2008) have extended it to the study of the segmentation of causal chains in four languages (Ewe,
} 
Johnson-Laird (1976:527), 'verbs that describe how people and things change their places and their orientations in space' are 'the most characteristically verbal of all the verbs', 'their purest and most prototypical forms', which provide a model for the expression of nonspatial events. Hence, among children, 'verbs that describe movement are first learned, most frequently used, and conceptually dominant.' Moreover, 'not only are verbs of motion ontogenetically primary, but their meanings have a strongly perceptual basis.' This makes it easy for us to encode motion scenarios in animated video stimuli, which is an ideal way to ensure comparable referential content in event descriptions across languages. In addition, a typology of the lexical component of motion-event descriptions has already been proposed-in Talmy's $(1985,2000)$ work on 'lexicalization patterns' - and the semantic typology of motion-event segmentation can build on it. Talmy's typology describes the encoding of PATH functions (information about where (to/past/from) an object moves) in verb roots (VERB-FRAMING) vs. outside the verb (SATELLITE-FRAMING). It turns out that the place of a language within this typology is one factor in determining how many and what kinds of path segments can be syntactically combined in the language.

Semantic typology proceeds by mapping the extensions of language-particular semantic categories on some ETIC GRID, a possibility space created by a few independent notional dimensions in which every categorized stimulus can be located as a data point. For instance, studies of kinship terminology employ a network of generic genealogical relations as an etic grid-abstracting, at least at this stage, from the culture-specific construal of marriage and descent relations. Berlin and Kay's seminal study of color terminologies, following Brown \& Lenneberg 1954, famously used the Munsell color chart - a matrix of forty hues by eight brightness values, realized in 320 color chips (to which was added one white and one black chip and eight chips of gray in the same eight degrees of brightness realized in the chips featuring hue). The case study we focus on here examines the encoding of complex motion events, in the sense of stimuli in which some FIGURE (Talmy 1985) changes location with respect to a series of referential GROUNDS. Language-specific constraints on the encoding of such stimuli turn out to be sensitive to the type and number of location changes that are encoded. The etic grid in this case consists of a series of possible combinations of location-change subevents. Each of these subevents is defined in terms of its temporal position in the sequence and a set of geometrical relations between the figure and a ground that characterizes the change. We adopt the framework developed by Jackendoff (1983:161-87) to label the cells of the grid. The framework should not be confused with the grid; the cells of the grid are independent of assumptions about language and/or cognition.

How should linguistic event segmentation be measured? Previous studies have taken syntactic units (Pawley 1987) or intonational units (Givón 1991) as criteria. But such units are language-specific in terms of their internal complexity and therefore incomparable as measures of event segmentation (see \$2). Our proposed starting point is the MACRO-EVENT PROPERTY (MEP), a property of constructions that assesses the event construal they convey-specifically, the 'tightness of packaging' of subevents in the construction. A construction has the MEP if temporal operations such as time adverbials, temporal clauses, and tenses necessarily have scope over all subevents encoded by the construction. We present a study of the constraints that eighteen genetically and

Japanese, Lao, Yukatek). Van Staden and Reesink (2008) apply the macro-event property to the semantic typology of serial verb constructions in Austronesian and Papuan languages independently of semantic domain. 
typologically diverse languages impose on the segmentation of complex motion events into constructions that have the MEP (MACRO-EVENT EXPRESSIONS). We identify several types of languages (see Figure 2 below). In type-I languages, it is possible to integrate subevents of departure from 'source', arrival at 'goal', and passing of an intermediate 'route' ground into a single macro-event expression ('Floyd went from Nijmegen across the river to Elst'). Type-II languages permit integration of departure and arrival, but require a separate macro-event expression for the encoding of some-though not all (see the discussion in $\$ 5$ for details) — passing events ('Floyd went from Nijmegen to Elst, crossing the river'). In type-III languages, location change with respect to each ground must be encoded in a separate macro-event expression ('Floyd left Nijmegen, crossed the river, and arrived in Elst'). Lexicalization patterns and the availability of certain kinds of multiverb constructions jointly determine which of these types a language instantiates. Type-I languages are either satellite-framed on Talmy's typology, or they have SERIAL VERB or MULTIVERB constructions that permit combinations of multiple location-change-denoting verb phrases in single macro-event expressions. Type-II languages are verb-framed (some exclusively so, others predominantly); but they all in addition express path functions to some extent outside the verb, and so to a limited extent enable reference to multiple location-change grounds in a single verb phrase. Type-III languages lexicalize path functions exclusively in verb roots and lack constructions that integrate multiple location-change-denoting verb phrases.

We also found a number of principles of form-to-meaning mapping ('correspondence rules', in the parlance of Jackendoff 1983, 2002) governing the segmentation of motion events across macro-event expressions that are shared across all languages in our sample. Some of these seem to fall out from more general principles of event encoding. For instance, the well-known principle of biunique assignment of thematic relations (Bresnan 1980, Chomsky 1981:36, Fillmore 1968, Jackendoff 1990:59-70, inter alia) applies to the encoding of path functions in macro-event expressions. An important finding here, suggested by the study of multiverb constructions, is that such principles are sensitive to the MEP, rather than to any level of syntax (such as the clause or verb phrase). Other principles appear to be domain-specific, for example, the unique vector constraint, a constraint on the encoding of direction information in macro-event expressions. These macro-event-encoding principles have important implications for the structure of the syntax-semantics interface, as explored below.

2. Previous research. Previous studies of crosslinguistic variation in event segmentation adopted syntactic units (Pawley 1987) or intonational units (Givón 1991) as criteria. Pawley (1987) compares event descriptions in the East New Guinea Highlands language Kalam to approximate English equivalents that might be used in the same contexts. The unit of comparison is the 'conceptual event', defined as the meaning of a clause containing a single 'event classifier', that is, verb. Pawley refers to Chafe $(1977,1979)$ and Grace $(1981,1987)$, who argue that clauses correspond to basic mental processing units in the on-line production of narratives. Pawley asks to what extent the sets of possible conceptual events in English and Kalam overlap, unearthing striking differences between the two languages. Thus, Kalam lacks 'episodic' verbs, that is, verbs that lexicalize script-level action sequences. For instance, there is no simple verb that means 'hunt.' Instead, hunting activities are conventionally construed as sequences of four to six conceptual events. Pawley also addresses differences in event segmentation between English and Kalam that he attributes to 'differences in the treatment of case relations.' One domain where these manifest themselves is the representation of 
motion events. Thus, to encode a pragmatic equivalent of 2 , Kalam requires a minimum of four verbs distributed over three clauses, as in $3 .^{3}$

(2) The man threw a stick over the fence into the garden.

(3) B monday d yokek, waty at amb, wog-mgan yowp. man stick hold he.displaced.Ds fence above it.went garden-inside it.fell

'The man threw a stick over the fence into the garden.'

(Kalam; Pawley 1987:354)

The difference in lexicalization between the two languages is obvious. But does it amount to a difference in what is semantically represented as an instance of an event category? A first problem is that events are represented in language and cognition as having mereological (i.e. part-whole) structures where parts and combinations of events are themselves conceptualized as instances of events (e.g. Casati \& Varzi 1999, Krifka 1998, Zacks \& Tversky 2001). So even if the motion event is broken down into three or four conceptual events in 3 , these still add up to a representation of a single motion event. All of the events represented in War and peace may be conceived of as parts of a single event - so may the entire history of the universe. Hence, taking any particular unit of syntax as the criterion of event segmentation remains a relatively arbitrary move, unless some semantic motivation exists to single out that unit of syntax. A second problem is that syntactic relations between the verbs, verb phrases, and clauses in 3 may vary - some are apparently more tightly integrated syntactically than others. Should one assume that such differences do not affect the semantics of the event representation?

The latter problem is addressed in a response to Pawley by Givón (1991). Givón compares on-line and off-line descriptions of a video stimulus in four Papuan languages (including Kalam), which make heavy use of serial verb and CLAUSE-CHAINING constructions, and in Tok Pisin (or Neo-Melanesian, the English-based Creole used as a lingua franca in Papua New Guinea), which has few serial verb constructions and no chaining. Givón's study measures the likelihood of pauses of a certain length to occur in various syntactic positions. He finds that the likelihood of pauses is significantly lower inside serial verb constructions than elsewhere, regardless of language. This is presented as evidence that 'serial verb constructions do not represent a different cognitive way of segmenting reality' (Givón 1991:120). Pauses may not be a very reliable measure of event segmentation either, however, since they are likely to reflect a host of factors in addition to semantics (including phonological, syntactic, and pragmatic properties; cf. Levelt 1989:256-60, 385-87). Nevertheless, Givón's study suggests that serial verb constructions in Kalam form tighter syntactic units than clause-chaining constructions and sequences of independent clauses. This has important consequences for the use of any particular level of syntax such as the clause or verb phrase as a criterion of event segmentation. To make this point clearer, compare the constraints that English and Ewe (a Gbe language of the Kwa family within Niger-Congo, spoken in Ghana and Togo) impose on the encoding of motion events. Examples 4 and 5 illustrate the most densely packaged descriptions available in English and Ewe that encode all location-

\footnotetext{
${ }^{3}$ Key to abbreviations in morpheme glosses: 1: first person, 3: third person, A: 'Set-A' (ergative/possessor) cross-reference, ABL: ablative, ABS: absolutive, ACAUS: anticausative, ACC: accusative, ALL: allative, AUX: auxiliary, в: 'Set-B' (absolutive) cross-reference, CL: classifier, CMP: completive, Con: converb form, CONJ: conjunct (participle), DAT: dative, DEF: definite, DIM: diminutive, DIR: direction(al), DS: different subject, D1: proximal (exophoric) deictic particle, D2: distal deictic/anaphoric particle, EVID: evidential, GEN: genitive, IMPF: imperfective, IN: inanimate, INC: incompletive, INST: instrumental, ITI: itive (directional), LOC: locative, M: masculine, NEG: negation, NOM: nominative, ORD: ordinal, PAST: past tense, PERF: perfect, PL: plural, PRES: present tense, PRV: presentative, PRT: participle, REP: repetitive, SG: singular, TOP: topic, VEN: ventive (directional).
} 
change subevents of the scenario depicted in Figure 1 (a red circle rolling from a blue square past a brown house-shaped object to a green triangle; this is our stimulus clip ECOM B5; see $\$ 4$ and the list of stimuli in Appendix B).

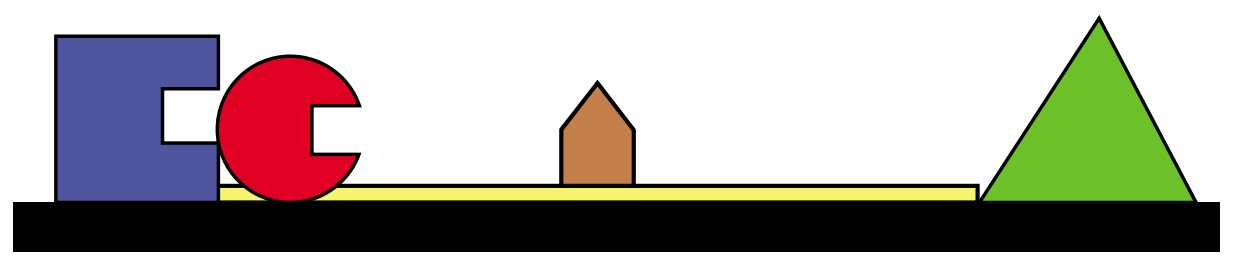

FIGURE 1. First frame of ECOM B5.

(4) The circle rolled from the blue square past the house-shaped object to the green triangle.

(5) Circle lá mli tsó bluto gbó le mó-á dzí tó xo-a [circle DEF roll from blue place LOC road-DEF top] $\mathrm{VP}$ [pass house-DEF yú yi dé triangle lá gbó.

skin $]_{\mathrm{VP}}$ [go ALL triangle DEF place $]_{\mathrm{VP}}$

'The circle rolls from the blue place on the road, passes the side of the house, goes to the triangle.'

(Ewe)

Where English makes do with a single VP, Ewe requires three. So if the VP is the standard of comparison, the two languages differ dramatically in event segmentation. But is the VP an appropriate category for comparison? The three VPs in 5 arguably together form a single clause, since it is impossible in this kind of construction to negate one VP without negating the entire sentence. In Ewe, sentence negation is expressed simultaneously by mé preceding the first verb and $o$ in final position. All the verbs in the clause are then within the scope of the negation. This is shown in $5^{\prime}$, the negation of 5 .

(5’) Circle lá mé-mli tsó bluto gbó le mó-á dzí tó xo-a circle DEF NEG-roll from blue place LOC road-DEF top pass house-DEF yú yi dé triangle lá gbó o. skin go ALL triangle DEF place NEG

'The circle didn't roll from the blue place on the road, pass the side of the house, go to the triangle.'

It is not possible for negation to have scope over just one single verb phrase in 5 , and not the others. This is shown by the unacceptability of the sentence below where negation of the second VP is attempted.

$\left(5^{\prime \prime}\right) *$ Circle lá mli tsó bluto gbó le mó-á dzí mé-tó xo-a circle DEF roll from blue place LOC road-DEF top NEG-pass house-DEF yú yi dé triangle lá gbó o. skin go ALL triangle DEF place NEG

Intended: 'The circle rolled from the blue place on the road, did not pass the side of the house, went to the triangle.' 
The intended meaning of $5^{\prime}$ requires a biclausal structure. In the present article, we rely on the criterion of lack of independent negation as a crosslinguistically applicable test for clausehood. The ability to string together multiple VPs in a single clause without involving subordination sets VPs in Ewe apart from those in English. How, then, can we be sure that in comparing Ewe VPs to English VPs, we are not comparing the proverbial apples and oranges? Suppose, for the sake of the argument, that there was a typological 'parameter' that prescribed the use of serialized VPs in languages such as Ewe for the encoding of certain semantic relations that are expressed by PPs in languages such as English. ${ }^{4}$ Would it not seem, then, that in terms of event segmentation-and form-to-meaning mapping more generally-some Ewe VPs ought to be compared to English VPs and other Ewe VPs to English PPs? ${ }^{5}$

The problem cannot be avoided simply by using clauses instead of VPs as the yardstick of segmentation. There is a second multiverb construction in Ewe that could likewise be used to describe the scenario in Fig. 1 and that likewise consists of multiple VPs combined into a single clause without subordination.

(6) Circle lá mli tsó bluto gbó le mó-á dzí vá tó xo-a [circle DEF roll from blue place LOC road-DEF top $]_{\mathrm{VP}}$ [VEN pass house-DEF yú hé vá yi dé triangle lá gbó.

skin $]_{\mathrm{VP}}$ [ITI VEN go ALL triangle DEF place $]_{\mathrm{VP}}$

'The circle rolled from the blue place on the road, passed the side of the house, went to the triangle.'

(Ewe)

Morphologically, the difference between the two constructions consists of the presence of directional particles vá 'ventive' and hé 'itive' in 6. These particles derive from motion verbs, but their use is not restricted to motion-event descriptions. ${ }^{6}$ Distributional evidence suggests that these are not coordinators or complementizers. The construction in 6 can convey a great deal more information about a motion event than the construction in 5. As shown in $\S 6$, the construction in 6 is able to accommodate multiple goals and multiple direction vectors, making it correspond to a multi-VP or multiclause construction in English. But an analysis using clausehood as the criterion of event segmentation would be unable to express the difference between 5 and 6 .

The problem is incomparable standards of comparison. Ideally, we want something like an 'event phrase' - a single universal unit of syntax dedicated to the encoding of events - such that we could ask how much information about a motion event is encoded in this phrase in different languages. Instead, every language has multiple syntactic

\footnotetext{
${ }^{4}$ To be perfectly clear, we do not wish to suggest that this is the case-at best, it is a gross oversimplification. But if it were the case, a translation of 4 in Ewe would look something like 5.

How can one know that $m l i$ 'roll', tó 'pass', and $y i$ 'go' in 5 are not prepositions? Ewe has both prepositions (derived from verbs) and postpositions (derived from nouns). Verbs differ from prepositions in at least two respects: verbs can be marked for habitual aspect; and verb phrases, unlike prepositional phrases, cannot be topicalized. See Aboh et al. 2007, Ameka 2003, and Ameka \& Essegbey 2006 for further evidence and discussion.

${ }^{5}$ There is a considerable body of research on typological and diachronic relationships between adpositional phrase constructions and serial verb constructions; see, for example, Schiller 1989 and references therein.

${ }^{6}$ The directional particles hé ('itive', related to the homophonous verb meaning 'go' (departure from deictic center or indexically determined location)) and vá ('ventive', related to the homophonous verb meaning 'come' (arrival at deictic center or indexically determined location)) belong to the class of preverbs of Ewe. These are forms that mark functional categories such as aspect, modality, and voice on verbs. Preverbs differ from verbs in that they do not head VPs, do not inflect for habitual aspect, and do not take NP or PP complements (cf. Ameka 1991, 2005a,b, Ansre 1966).
} 
categories all charged with the function of event encoding, and the cut-off points between these categories do not agree across languages. As it stands, a typology of linguistic event segmentation based on verb phrases or clauses would at best be a typology of the semantics of verb phrases or clauses. It would not tell us directly about the constraints different languages impose on the segmentation of events of a certain kind. In the absence of a universal 'event phrase', the best we can aim for is a property of constructions that singles out those constructions in each language that package the information about an event in comparable ways. This is the macro-event property introduced in the next section.

3. The MACRo-EVEnT PROPERTy. We require a metric of event segmentation that is sensitive to the syntax of event-denoting constructions, but at the same time can be applied across languages regardless of construction type. This should be a property of constructions that assesses how they package event-related information and that can be readily tested in any language. The property should single out 'event phrases' that segment linguistic event representations in ways that can be meaningfully compared across languages. Intuitively, the issue here is one of 'coherence' or 'compactness' of packaging. Consider again 1, repeated here as 7 for convenience.

(7) a. Sally broke the vase.

b. The vase was broken by Sally.

c. Sally knocked over the vase and it broke.

d. Sally broke the vase by knocking it over.

e. Sally knocked over the vase. It broke.

f. The vase broke. Sally knocked it over.

g. The vase broke because Sally knocked it over.

h. Sally hit the vase. It fell and broke.

Intuitively, one might want to say that cause and effect are presented as a single event in $7 \mathrm{a}, \mathrm{b}$, but as a sequence of two events in $7 \mathrm{c}$ and $7 \mathrm{e}-\mathrm{g}$. The status of $7 \mathrm{~d}$ seems somewhat unclear in this regard, and in $7 \mathrm{~h}$, the effect of what Sally did to the vase seems to be further broken down into two events. And yet, it is clear in all cases that the encoded events are subevents of a larger event of Sally breaking the vase. How to operationalize the intuition that this superordinate event is presented as a single event in some cases and as a sequence of multiple events in others? Assume that events as an ontological category of cognition are individuated by temporal properties such as their beginning and/or end in time, their duration, and their position on the timeline with respect to other events or some calendrical scale. ${ }^{7}$ While all subevents in 7 always have these properties conceptually, they cannot always be made explicit linguistically - that depends on the construction; see the examples in $7^{\prime}$.

\footnotetext{
${ }^{7}$ We assume that a state of affairs that has no boundaries in time is 'atemporal' (Langacker 1987). We draw a distinction between such 'individual-level' states (Carlson 1977) and 'stage-level' states which are time-bounded, tacitly subsuming the latter under the term 'event', as the difference does not matter for our purposes. It might seem that temporal properties apply to objects as well. More precisely, however, it is the existence of objects that is characterized by temporal boundaries, duration, and a location on the timelineexistence is a time-bounded state. One way to see that temporal properties are not properties of objects per se is to imagine a 'time slice' out of the history of an event, defined in terms of its boundaries, duration, and temporal position. This time slice is readily recognized as a part of the event. In contrast, the corresponding time slices out of the history of an object are not considered parts of the object. There is a considerable body of philosophical literature on the problem of event individuation. Useful overviews both of this literature and of attempts to deal with the problem in linguistic theory can be found in Parsons 1990 and Pianesi \& Varzi 2000 .
} 
(7) $a^{\prime}$. Sally broke the vase instantly/a moment later.

$c^{\prime}$. Sally knocked over the vase and it broke instantly/a moment later.

$c^{\prime \prime}$. Sally knocked over the vase instantly/a moment later and it broke.

The subevents of Sally's knocking over the vase and its breaking are located in time individually by the adverbials instantly and a moment later in $7 \mathrm{c}^{\prime}, \mathrm{c}^{\prime \prime}$. Consequently, in $7 \mathrm{c}^{\prime \prime}$, the adverbials are understood to quantify over the temporal distance between Sally's knocking over the vase and some other event mentioned previously, whereas in $7 \mathrm{c}^{\prime}$, they refer to the distance between the knocking over and the breaking of the vase. In $7 \mathrm{a}^{\prime}$, however, the same adverbials have to be understood as denoting intervals that encompass both the time of the vase breaking and the time of whatever Sally did to cause it. This is a syntactic property, not merely an artifact of the use of a single verb. The resultative construction in 8 patterns with the single verb in $7 a^{\prime}$.

(8) a. Floyd instantly pushed the door shut.

b. Floyd pushed the door instantly and it shut.

c. Floyd pushed the door and it shut instantly.

Again, in 8b, instantly quantifies over the distance between the pushing event and some event mentioned earlier. In $8 \mathrm{c}$, it refers to the distance between the pushing and the shutting event; and in $8 \mathrm{a}$, it specifies the distance of the combination of pushing and shutting with respect to some point of reference introduced before. We can use this property to assess the event segmentation in $7 \mathrm{~d}$ and $7 \mathrm{~g}$, both of which involve subordinate clauses.

(7) $d^{\prime}$. 'Sally broke the vase as it hit the floor by knocking it over.

$\mathrm{e}^{\prime}$. Sally knocked over the vase. It broke as it hit the floor.

$\mathrm{g}^{\prime}$. The vase broke as it hit the floor because Sally knocked it over.

As $7 \mathrm{e}^{\prime}$ shows, the temporal clause as it hit the floor can denote a time interval that includes only the breaking subevent, but not Sally's action, provided the former modifies an independent clause. The same holds for the causal clause construction in $7 \mathrm{~g}^{\prime}$, but not for the one in $7 \mathrm{~d}^{\prime}$. Since the by clause merely specifies the causal subevent already encoded by the transitive main-clause verb, $7 \mathrm{~d}^{\prime}$ forces an interpretation according to which both subevents happened when the vase hit the ground, which is strange. ${ }^{8}$

Similar effects can be observed in the encoding of motion events. It is possible in English (although, as seen below, in many languages it is not) to encode motion along a path determined by source, goal, and even a 'route' (Jackendoff 1983) in between, in a single clause or verb phrase. It is, however, not possible to 'time' the corresponding phases of the event; this requires multiple verb phrases. The intended meaning of $9 \mathrm{~b}$ is easy enough to recover, and yet the sentence is clearly ill-formed.

(9) a. Floyd went from Rochester via Batavia to Buffalo.

b. *Floyd went from Rochester at seven via Batavia at seven forty-five to Buffalo at eight thirty. ${ }^{9}$

\footnotetext{
${ }^{8}$ The observation that differences in syntactic packaging result in differences in form-to-meaning mapping, including in the division of labor between semantics and pragmatics, goes back to the generative semantics debate; see, for example, Fillmore 1972, Fodor 1970, and Wierzbicka 1980:162-63.

${ }^{9}$ We are grateful to Brian Joseph for pointing out the following at least marginally acceptable variant: ? Floyd went from Rochester at 7:00 on to Buffalo at 8:30 with a stop in Batavia at 7:45. As he observes, what makes this more acceptable is primarily the event nominal stop, which licenses its own time-positional adverbial (see discussion of this effect below). Furthermore, the presence of this event nominal may invite an eventive reinterpretation of the other two PPs. A suitable scenario might be one tracking Floyd's progress through a busy day - for example, with Floyd having meetings in Rochester and Buffalo-rather than to merely report a motion event.
} 
c. Floyd left Rochester, passed through Batavia, and arrived in Buffalo.

d. Floyd left Rochester at seven, passed through Batavia at seven fortyfive, and arrived in Buffalo at eight thirty.

Events as intentional objects of cognitive representations are individuated by the spacetime regions they occupy. The individuation of the subevents of departure, passing, and arrival can be made explicit in 9c (witness 9d), but not in 9a (witness the unacceptability of $9 \mathrm{~b}$ ). The subevents in $9 \mathrm{a}$ are not temporally individuated inasmuch as they are syntactically packaged so tightly as to not admit individual access by temporal operators. For instance, only time-positional adverbials denoting intervals that can accommodate all subevents may combine with 9a.

(10) a. 'Floyd went from Rochester via Batavia to Buffalo at seven/eight thirty. b. Floyd went from Rochester via Batavia to Buffalo in the morning.

We submit that the relevant difference between the constructions in 7-9 lies in the packaging properties of the constructions featured in the two descriptions, or more generally, in constraints on form-to-meaning mapping associated with the constructions. We propose that the difference can be captured in a single property, which we term the macro-event property (MEP). ${ }^{10}$ Examples 7a,b and d have the MEP; so do 8a and 9a. The other examples quoted above in this section lack the MEP. For a formal definition of the MEP — focusing just on time-positional operators ${ }^{11}$ — we adopt the model-theoretic treatment of event semantics originally proposed by Davidson (1967) and further advanced, for example, in Parsons 1990. In this approach, natural-language expressions with event reference are treated as denoting properties of events. These properties are modeled in predicate logic by predicates over an existentially bound event variable. We assume a subevent relation $\leq_{E}$ which defines a partial order among subevents; to be more precise, $\leq_{E}$ is reflexive, transitive, and antisymmetric $\left(\leq_{E}\right.$ constitutes a join semilattice via a primitive mereological sum operation; see, for example, Krifka 1998: 199-207). We furthermore assume that time-positional adverbials, temporal clauses, and tenses denote a time-positional operator AT as defined in 11.

(11) $\mathrm{AT}:=\lambda P \lambda t \exists e . P(e) \wedge \tau(e) \subseteq t$

The variable $t$ ranges over time intervals and $\tau(e)$ is a 'temporal trace' function that returns the 'run time' of event $e$. AT maps an event $e$ that falls under a predicate $P$ into a time $t$ that contains the run time of $e .^{12}$ The value of $t$ may be determined by some other event description (after breakfast; during Floyd's visit to Nijmegen; as she was heading down the driveway) or through specification of a calendrical time interval (in the morning; on Monday; at 3pm). Then the MEP may be defined as in 12.

(12) Let expression $\mathrm{C}$ denote an event predicate $P(\llbracket \mathrm{C} \rrbracket=\exists e . P(e))$. Let $\mathrm{T}_{\mathrm{POS}}$ be any modifier of $\mathrm{C}\left(\left[\ldots \mathrm{T}_{\mathrm{POS}} \ldots\right]_{\mathrm{C}}\right)$ that locates some subevent $e^{\prime} \leq_{E} e$

\footnotetext{
${ }^{10}$ The term 'macro-event' was coined in Talmy 1991, 2000. We talk here about the macro-event PROPERTY of form-to-meaning mapping. We do not see any reason for stipulating an ontological category of macroevents, and we do not claim that macro-events are a part of extralinguistic reality. We do not even maintain that macro-events have a language-independent reality in nonlinguistic cognitive representations of reality (although we do consider this an empirical question; see $\$ 7$ ).

${ }^{11}$ Definitions in terms of duration operators or aspectual operators that access the boundaries of events have a straightforwardly analogous format.

${ }^{12}$ Definition 11 does not capture the semantics of 'topic time' adverbials (in the sense of Klein 1994), which do not locate states or events in time, but constrain the time for which the truth of a proposition is asserted, questioned, and so forth. In semantically imperfective clauses, topic time adverbials specify times that are included in the run time of the event or state, for example, At noon, it was raining/the sky was blue.
} 
at time $t\left(\llbracket \mathrm{T}_{\mathrm{POS}} \rrbracket=\lambda Q \lambda t \exists e^{\prime}\left[Q\left(e^{\prime}\right) \wedge \tau\left(e^{\prime}\right) \subseteq t\right]\right.$, where $Q$ may or may not be identical to $P$ ). Then $\mathrm{C}$ has the macro-event property (MEP) iff any syntactically and semantically acceptable $\mathrm{T}_{\mathrm{POS}}$ necessarily also locates $e$ at $t$ (i.e. $\operatorname{AT}\left(Q, e^{\prime}, t\right) \rightarrow \operatorname{AT}(P, e, t)$ for any acceptable $\left.\mathrm{T}_{\mathrm{POS}}\right)$.

That is, an expression has the MEP iff any time-positional operator denoted by a timepositional adverbial, temporal clause, or tense that 'locates' a subevent entailed by the expression in time also locates all other subevents in time. For example, the singleclause motion description in 9a has the MEP since the only time-positional operators it admits denote time intervals that include the run times of the three subevents of departure, passing, and arrival together-witness 10 .

Future research has to show whether 12 needs to be replaced with a narrower definition. For example, one could require that for a construction to have the MEP, it must disallow temporal operators that do not have scope over the event in its entirety altogether. One referee suggests that this might be the case, with reference to 13 .

(13) The sheriff of Nottingham jailed Robin Hood for four years. (Dowty 1979:58)

The example has two interpretations: one in which the for-adverbial refers to the duration of the event time interval and the VP is understood iteratively, and one in which the VP is interpreted as an accomplishment and the for-adverbial quantifies the duration of the result state. In this case, however, the adverbial actually has scope over no part of the event described by the construction, since the result state is not a part of that event (at most, the inception of the result state is), and so 13 does have the MEP according to 12 (or rather, a version of 12 defined for durational, rather than timepositional, modifiers).

Let us briefly consider further the relationship between the MEP and syntax. Verbs commonly provide a lexical classification of kinds of events (Parsons 1990) that are encoded along with their participants by the syntactic projections of verbs, that is, by verb phrases. English VPs generally have the MEP, but there are exceptions. Consider the effect of 'event nominals' (e.g. Zucchi 1989).

(14) The Franco-Russian War lasted from the invasion of Russia by the Grande Armee in 1812 to the Battle of Leipzig in 1813.

In 14, the NPs the invasion of Russia by the Grande Armee and the Battle of Leipzig each license a time-positional adverbial, since they denote events. As a result, the VP loses the MEP. This makes sense in view of the fact that the NPs in 14 have themselves VP-like properties (Fu et al. 2001, Grimshaw 1990, Levi 1978, Nunes 1993). Specifically, the event nominals that head these NPs license time-positional adverbials. This is the immediate cause of the loss of the MEP.

Another way of 'lifting' the MEP in English VPs is by introducing coordination.

(15) Floyd went from Rochester via Batavia to Buffalo in the morning and (on) to Pittsburgh in the afternoon.

The ability to have a time adverbial in the second conjunct is presumably tied to a VPellipsis ('gapping') parse of 15 , as opposed to a coordination of prepositional phrases. ${ }^{13}$ There is thus a relatively straightforward syntactic reason why coordination may constitute an exception to VPs having the MEP. However, phrasal coordination under various

\footnotetext{
${ }^{13}$ Another way in which ellipsis may create a multi-macro-event expression with only a single surface verb form is through deletion of an underlying complement. For instance, McCawley (1988:654) argues that the multiplicity of time adverbials in Last week John wanted the apartment in July(, but now he wants it in August) is a reflex of an ellipsed complement of want (to have, to rent, etc.).
} 
different thematic relations - for example, under a theme role, as in 16a-may introduce a choice between a collective and a distributive reading. The distributive reading is tantamount to a multiple-event interpretation (in 16a, an interpretation involving two eating events). ${ }^{14}$ The event-semantic interpretation of 16 a under the distributive reading is not qualitatively different from that of the multi-macro-event expression in 16b. The fact of the semantic representation of multiple events is merely made more explicit by the presence of the time adverbials.

(16) a. Floyd ate an apple and an orange.

b. Floyd ate an apple in the morning and an orange in the afternoon.

According to 12, a construction has the MEP if and only if it cannot be modified by time-positional operators that have scope over proper subevents. But 12 mentions only time-positional operators that do not change the categorical properties of the construction. The question of whether 16a has the MEP thus comes down to the question of whether there is a nonelliptical analysis of $16 \mathrm{~b}$, that is, one under which $16 \mathrm{~b}$ has the same syntactic structure as $16 \mathrm{a}$, except for the time adverbials. We merely note that coordination lifts the MEP at least to the extent that it involves gapping.

In sum, there are exceptions to the association between the English VP and the MEP, but these are principled exceptions. ${ }^{15}$ The principled nature of the exceptions has convinced us that the MEP is a property of construction types. What about constructions larger than the VP? We have already seen one example of a multiclausal construction in English that appears to have the MEP, namely, the by-gerund construction in $7 \mathrm{~d}$. So-called serial verb or multiverb constructions in other languages may (but need not) likewise have the MEP. ${ }^{16}$ Consider again the Ewe examples in 5-6 above. The 'plain' multiverb construction in 5 has the $\mathrm{MEP}$ - any time-positional operator in 5 must have scope over all three VPs. Hence, $5^{\prime \prime \prime}$ is ungrammatical. If one wishes to 'time' the subevents of departure, passing, and arrival, one has to use minimally the 'augmented' construction in 6 , which involves the directional particles vá ('ventive') and hé ('itive').

$\left(5^{\prime \prime \prime}\right)$ *Circle lá mli tsó bluto gbó le mó-á dzí le ga enyí me [circle DEF roll from blue place LOC road-DEF top at hour eight in] $]_{\mathrm{VP}}$ tó xo-a yú le ga asiéke me [pass house-DEF skin at hour nine in] $]_{\mathrm{VP}}$ yi dé triangle lá gbó le ga ewó me.

[go ALL triangle DEF place at hour ten in] $]_{\mathrm{VP}}$

Intended: 'The circle rolls from the blue place on the road at eight o'clock, passes the side of the house at nine o'clock, goes to the triangle at ten o'clock.'

(Ewe)

\footnotetext{
${ }^{14}$ See Landman 2000 and references therein on the related problem of distributive vs. collective interpretations of plurals from an event-semantic perspective.

${ }^{15}$ Another such principled exception to the alignment between VPs and the MEP concerns iterative and habitual reference; see Bohnemeyer 2003 for some discussion.

${ }^{16}$ In the literature on serial verb structures, the criterion of reference to a 'single event' is often used to define such constructions (e.g. Baker 1989:547, Dixon 2006:339, Osam 1994:193, Schiller 1989:405-6, Sebba 1987:112). Other authors distinguish between 'single-event' and 'multi-event' serial verb constructions (e.g. Dechaine 1993 and references therein). Either way, the MEP makes it possible to operationalize such intuitions. We do not at present wish to take a position on whether multiverb constructions (not integrated by overt complementizers or connectives) that lack the MEP should or should not be considered serial verb constructions; we merely observe that such constructions clearly exist, as exemplified in $6^{\prime}$ for Ewe and below in 24 for Lao.
} 
(6') Circle lá mli tsó bluto gbó le mó-á dzí le ga enyí me [circle DEF roll from blue place LOC road-DEF top at hour eight in] $]_{\mathrm{VP}}$ vá tó xo-a yú le ga asiéke me [VEN pass house-DEF skin at hour nine in] $]_{\mathrm{VP}}$ hé vá yi dé triangle lá gbó le ga ewó me. [ITI VEN go ALL triangle DEF place at hour ten in] $]_{\mathrm{VP}}$

'The circle rolled from the blue place on the road at eight o'clock, passed the side of the house at nine o'clock, went to the triangle at ten o'clock.'

(Ewe)

Recall that both 5 and 6 are monoclausal. Thus, language-specific multi-VP constructions may have the MEP, but clausehood is not a universal predictor of the MEP.

Let us also briefly consider the relationship between the MEP and the semantic and conceptual properties of event representations. The MEP is a property of constructions that describes how they 'package' information about events-namely, in such a way as to license only temporal operators that have scope over all subevents. This does not entail anything about the kinds of events such constructions can refer to. We do not claim that there is an ontological type of 'macro-events', with distinct conceptual properties, that expressions that have the MEP denote. For example, we do not claim that the subevents of events described by macro-event expressions must be temporally contiguous. Consider 17, based on Rappaport Hovav \& Levin 2001 (and pointed out to us by a referee).

(17) a. Kelly sang herself hoarse.

b. *Kelly sang herself hoarse yesterday, but she didn't become hoarse until today.

As Rappaport Hovav and Levin observe, the reflexive resultative is (or at any rate can be) 'temporally independent'; for 17a to be true, for example, it need not be the case that Kelly's singing and her being hoarse are contiguous. Yet, 17a has the MEP — witness the illformedness of $17 \mathrm{~b}$. How is this possible? The MEP is not a property of real-world events or their conceptualization, but a form-to-meaning mapping property of event descriptions. Specifically, the MEP regiments the behavior of event descriptions to which it applies vis-à-vis time adverbials_-and these properties are independent of whether the events described by such expressions are (conceived of as) uninterrupted or not. The utterance in $17 \mathrm{a}$ is perfectly compatible with Kelly's becoming hoarse the day after she sang; but it combines only with time adverbials that have scope over all subevents, including both the singing event and the event of becoming hoarse. We return to the relation between the MEP and the properties of internal cognitive event representations in $\S 7$.

In the remainder of this article, the MEP serves as a heuristic. We examine the encoding of complex motion events across languages, asking what constraints different languages impose on the segmentation of these events across macro-event expressions. We explore the extent of uniformity and variation in what parts of the stimuli are encoded by expressions that have the MEP. The MEP plays a role in this study comparable to the role of the 'conceptual event' unit in Pawley's (1987) comparison of Kalam and English discussed in $\$ 2$. The advantage of employing the MEP as the primary criterion in a typology of event segmentation is that it abstracts over language-specific constructions, permitting us to compare them in terms of how they package event reference. Moreover, as shown in $\S 6$, universal principles of event encoding at the syntax-semantics interface, such as the biuniqueness constraint on the assignment of thematic relations (Bresnan 1980, Chomsky 1981, Fillmore 1968, inter alia), are sensi- 
tive to the MEP. This suggests that the MEP is more than an otherwise arbitrary property that happens to be suitable for the purposes of a typology of event segmentation-that it has a substantive function in the human language faculty.

4. Design of the Study. The study was conducted with a two-pronged design, combining a questionnaire and a video stimulus. The questionnaire, called Event Integration Questionnaire, consisted of a structured list of complex event scenarios represented in a semantic metalanguage, to be used, not in direct elicitation, but as a checklist. The researchers were to collect renditions of the questionnaire scenarios in the target languages by whatever technique seemed applicable, including with the help of the video stimulus set (see Bohnemeyer 1999 for further details). The video stimulus set, the Event Complexity (ECOM) clips, comprised seventy-four short animated videos representing complex events involving a number of simple geometrical objects (circles, rectangles, triangles; cf. Bohnemeyer \& Caelen 1999). The researchers negotiated culturally appropriate renditions of the objects and their motions with the consultants. ${ }^{17}$ Both the questionnaire and the ECOM clips covered complex events in a variety of domains, including, within the motion domain, both the location-change sequences at issue here and scenarios integrating 'manner' components in the sense of Talmy (1985). Outside the motion domain, the clips depicted causal chains of various kinds (including events involving caused location change) and scenarios that involve 'transfer', or change of possession. In the present article, we focus on the encoding of information about the (change of) location of a moving figure with respect to some referential ground (Talmy 2000) or within some frame of reference (Levinson 1996). Other kinds of motion-event information, such as manner or 'path shape' (van der Zee 2000), are not considered here. The discussion in this and the following section is based on the framework for motion semantics proposed in Jackendoff 1983:Ch. 9; see Table 1.

\begin{tabular}{|c|c|c|c|}
\hline \multirow{3}{*}{$\begin{array}{l}\text { PATH TYPE } \\
\text { bounded paths }\end{array}$} & PATH FUNCTION & CORRESPONDING SUBEVENT & EXAMPLES \\
\hline & FROM (source) & departure & $\begin{array}{l}\text { from the entrance, off the } \\
\text { roof, out of the kitchen }\end{array}$ \\
\hline & To (goal) & arrival & $\begin{array}{l}\text { to the entrance, onto the } \\
\text { roof, into the kitchen }\end{array}$ \\
\hline routes & VIA (route) & passing & $\begin{array}{l}\text { past the entrance, across/ } \\
\text { over the roof, through } \\
\text { the kitchen }\end{array}$ \\
\hline directions & TOWARD; AWAY-FROM & $\begin{array}{l}\text { any phase of motion } \\
\text { oriented in a frame of } \\
\text { reference }\end{array}$ & $\begin{array}{l}\text { towards the entrance, } \\
\text { north(bound), down, } \\
\text { upriver, left(ward) }\end{array}$ \\
\hline
\end{tabular}

TABLE 1. Path functions according to Jackendoff 1983 and subevent decomposition.

We developed an etic grid of possible combinations of location-change subevents. In the following discussion, the subevents are referred to by the terms in Table 1. We encoded the combinations of location-change events in the questionnaire scenarios and stimulus items. A list of the questionnaire scenarios and stimulus items used in the collection of the data on which the analyses below are based can be found in the appendices.

\footnotetext{
${ }^{17}$ Several contributors to the study worked, instead of or in addition to ECOM, with the real-video stimulus Staged Events, developed by Miriam van Staden, Gunter Senft, Nick Enfield, and Jürgen Bohnemeyer specifically for issues of event encoding in multiverb constructions. Staged Events includes renditions of the ECOM scenarios featuring location-change sequences realized with a remote-controlled toy car moving around in a model landscape. See van Staden et al. 2001.
} 
Both the questionnaire and the ECOM clips were used to collect descriptions of complex stimulus events under two conditions: (i) the most natural descriptions of the various scenarios in the languages under investigation, and (ii) the most 'densely packaged' descriptions of the scenarios acceptable in the target languages, that is, those descriptions that made do with the smallest number of clauses, verb phrases, and morphemes while still entailing all relevant subevents (as prescribed in manuals accompanying the two tools).

Semantic typology depends on the collection of primary data from a wide range of genealogically independent and typologically diverse languages. This data collection should be, and often has to be, carried out in the field, and it can only be carried out by experts for the languages under investigation. Therefore, semantic typology is a collaborative effort. The language sample of the present study is the collection of the field languages of the researchers who collaborated on the study. The data were transcribed and archived by the researchers who recorded them. We analyzed the data in consultation with the contributors, discerning macro-event expressions from nonmacro-event expressions on the basis of the MEP and establishing what types of constraints macro-event expressions are subject to in a particular language. The eighteen languages on which the analysis summarized below is based are listed in Table 2, along with the populations the data were collected from and the researchers who collected them. Most researchers consulted with between three and five speakers; some worked with more. Table 2 also provides information about the classification of each language on Talmy's $(1985,2000)$ typology of lexicalization patterns in motion-event encoding, along with published sources beyond our data where available. The languages are sorted into 'verb-framed' and 'satellite-framed' (see §1), 'serializing' (using serial verb constructions for the combination of path and manner information; see Ameka \& Essegbey 2001, Zlatev \& Yangklang 2004), and 'split' (Talmy's term for Tzeltal, which lexicalizes path in verb roots, but uses these roots both in main verb and in 'directional' satellite forms). This classification emerges in the following section as one predictor of the number and type of path segments that can be integrated into a macro-event expression in a given language.

5. The SEgmentation of LOCATION-ChANGe SEQuenCES. In this section, we focus on the typological variation in how sequences of location-change subevents are segmented and distributed across macro-event expressions, while $\$ 6$ deals with form-tomeaning mapping principles that appear to be shared across languages. For convenience of presentation, we defer discussing the impact of direction encoding on event segmentation to $\S 6$, confining ourselves in the present section to the encoding of bounded path and route information (cf. Table 1$).{ }^{18}$

The languages in our sample fall into three types on the basis of how many and what kinds of location-change subevent representations they can integrate into the denotation of a macro-event construction. Type-I languages have clause- or phrase-level constructions that have the MEP and license combinations of maximally one departure, arrival, and passing subevent each, as in English. ${ }^{19}$

(18) a. The circle rolled from the square past the house-shaped object to the triangle in just 30 seconds.

\footnotetext{
${ }^{18}$ Directions differ from the other path functions in that they do not involve change of location; see $\S 6$.

${ }^{19}$ Strictly speaking, the question of whether there are (in any language) macro-event expressions that permit reference to more than one route ground remains unresolved. One does occasionally encounter examples such as Our final leg in the Across America North tour will take us across upper New York State thru the rolling
} 


\begin{tabular}{|c|c|c|c|c|}
\hline LANGUAGE & GENETIC AFFILIATION & $\begin{array}{l}\text { COUNTRY } \\
\text { (of data collection) }\end{array}$ & RESEARCHER & LEXICALIZATION TYPE \\
\hline Basque & isolate & Spain & $\begin{array}{l}\text { I. Ibarretxe- } \\
\text { Antuñano }\end{array}$ & $\begin{array}{l}\text { verb-framed } \\
\quad \text { (Ibarretxe-Antuñano } \\
\text { 2004b, 2007a) }\end{array}$ \\
\hline Dutch & $\begin{array}{l}\text { Indo-European } \\
\text { (West Germanic) }\end{array}$ & The Netherlands & $\begin{array}{l}\text { J. Bohnemeyer; } \\
\text { M. Caelen }\end{array}$ & $\begin{array}{l}\text { satellite-framed } \\
\text { (Talmy 2000) }\end{array}$ \\
\hline Ewe & Kwa (Gbe) & Ghana & $\begin{array}{l}\text { F. Ameka; } \\
\text { J. Essegbey }\end{array}$ & $\begin{array}{l}\text { serializing (Ameka \& } \\
\text { Essegbey 2001) }\end{array}$ \\
\hline Hindi & $\begin{array}{l}\text { Indo-European } \\
\text { (Indo-Aryan) }\end{array}$ & India & B. Narasimhan & $\begin{array}{l}\text { verb-framed } \\
\quad \text { (Narasimhan 2003) }\end{array}$ \\
\hline Jalonke & $\begin{array}{l}\text { Niger-Congo } \\
\text { (Western Mande) }\end{array}$ & Guinea & F. Lüpke & $\begin{array}{l}\text { verb-framed } \\
\quad \text { (Lüpke 2005) }\end{array}$ \\
\hline Japanese & isolate & Japan & S. Kita & $\begin{array}{l}\text { verb-framed } \\
\quad(\text { Talmy 2000) }\end{array}$ \\
\hline Kilivila & $\begin{array}{l}\text { Austronesian } \\
\text { (Papuan Tip) }\end{array}$ & Papua New Guinea & G. Senft & serializing (Senft 1999) \\
\hline Lao & $\begin{array}{c}\text { Tai-Kadai (East } \\
\text { Central Tai) }\end{array}$ & Laos & N. Enfield & $\begin{array}{l}\text { serializing } \\
\quad(\text { Enfield 2007) }\end{array}$ \\
\hline Marquesan & $\begin{array}{l}\text { Austronesian } \\
\text { (Central } \\
\text { Polynesian) }\end{array}$ & Marquesas & G. Cablitz & $\begin{array}{l}\text { satellite-framed } \\
\quad \text { (Cablitz 2002) }\end{array}$ \\
\hline $\begin{array}{l}\text { Mpwarntwe } \\
\text { Arrernte }\end{array}$ & Australian (Arandic) & Australia & D. Wilkins & $\begin{array}{l}\text { verb-framed } \\
\text { (Wilkins 2004) }\end{array}$ \\
\hline Saliba & $\begin{array}{l}\text { Austronesian } \\
\text { (Papuan Tip) }\end{array}$ & Papua New Guinea & A. Margetts & $\begin{array}{l}\text { serializing } \\
\quad \text { (Margetts 2004) }\end{array}$ \\
\hline Tidore & $\begin{array}{l}\text { West Papuan (North } \\
\text { Halmahera) }\end{array}$ & Indonesia & M. van Staden & verb-framed \\
\hline Tiriyo & $\begin{array}{l}\text { Carib (Wayana- } \\
\text { Trio) }\end{array}$ & Brazil & S. Meira & satellite-framed \\
\hline Trumai & isolate & Brazil & R. Guiradello & verb-framed \\
\hline Tzeltal & $\begin{array}{l}\text { Mayan (Cholan- } \\
\text { Tzeltalan) }\end{array}$ & Mexico & P. Brown & split (Talmy 2000) \\
\hline Yélî Dnye & $\begin{array}{l}\text { East Papuan (Yele- } \\
\text { Solomons) }\end{array}$ & Papua New Guinea & S. Levinson & $\begin{array}{l}\text { verb-framed } \\
\quad \text { (Levinson 2006) }\end{array}$ \\
\hline Yukatek & Mayan (Yucatecan) & Mexico & J. Bohnemeyer & $\begin{array}{l}\text { verb-framed } \\
\quad \text { (Bohnemeyer 2008) }\end{array}$ \\
\hline $\begin{array}{r}\text { Zoogocho } \\
\text { Zapotec }\end{array}$ & $\begin{array}{l}\text { Oto-Manguean } \\
\text { (Zapotec) }\end{array}$ & Mexico & A. Sonnenschein & verb-framed \\
\hline
\end{tabular}

TABLE 2. Languages in the ECOM/Questionnaire sample.

b. *The circle rolled from the square then past the house-shaped object finally to the triangle.

c. The circle rolled from the square, then passed the house-shaped object, and finally reached the triangle.

(19) a. Floyd went from Nijmegen to Amsterdam via Utrecht on the morning of June 8th.

b. *Floyd went from Nijmegen at eight to Amsterdam at nine thirty via Utrecht at nine.

farm country past Rochester (http://www.abbike.com/amNorth.htm). This seems fine as long as one assumes that the route grounds and the corresponding path segments overlap (as they do in this case) and the three path-denoting phrases are in some kind of direct (modifying or appositive) syntactic relation. In this case they form a single superordinate path phrase and do not violate the generalization. Where this is not the case, macro-event expressions with multiple route phrases become dubious, for example, ?Floyd hiked over the mountain through the valley. 
c. Floyd left Nijmegen at eight and reached Amsterdam at nine thirty, passing Utrecht at nine.

Examples 18a and 19a show that durational and time-positional adverbials with simple uncoordinated monoclausal representations have scope over all three subevents. 'Timing' of individual subevents, as required for the interpretation of the adverbs then and finally in $18 \mathrm{~b}$ and $19 \mathrm{~b}$, is impossible; it requires minimally multiple coordinated verb phrases, as in 18c and 19c. Macro-event expressions of this type are found in Dutch, Ewe, Lao, Marquesan, and Tiriyó. Example 20 is Tiriyó.

(20) Kau wewe-pisi enee-ja-n wewe-pəe əema-tae kanawa-pona. cow wood-DIM bring-PRES-EVID wood-from path-along vehicle-toward

'The cow is bringing the little stick from the tree along the path to the vehicle.'

(Tiriyó)

Ewe and Lao use a separate verb phrase for each location-change subevent. However, departure-, passing-, and arrival-denoting VPs may be combined in multiverb constructions to form single clauses (according to the negation criterion; cf. §2). This is illustrated for Ewe in 5 above; $5^{\prime \prime \prime}$ shows that this construction has the MEP. The case of Lao is similar, in that Lao, too, has multiverb constructions that integrate two or three location-change-denoting VPs into a single clause.

(21) Man $^{2}$ lèèn ${ }^{1}$ (qòòk ${ }^{5}$ ) caak ${ }^{5}$ hùan $^{2} \quad$ taam $^{3}$ thaang ${ }^{2}$ hòòt ${ }^{4}$ kòòn ${ }^{4}$-hiin ${ }^{3}$. [3 run exit from house $]_{\mathrm{VP}}[\text { follow path }]_{\mathrm{VP}}$ [reach CL-rock $]_{\mathrm{VP}}$ 'He ran (exited) from the house, followed the path, reached the rock.'

(Lao)

This Lao construction likewise has the MEP. To integrate separate time-locational operators in the individual VPs, no special morphemes are required. But intonation breaks need to be inserted (symbolized in 22 by a dash).

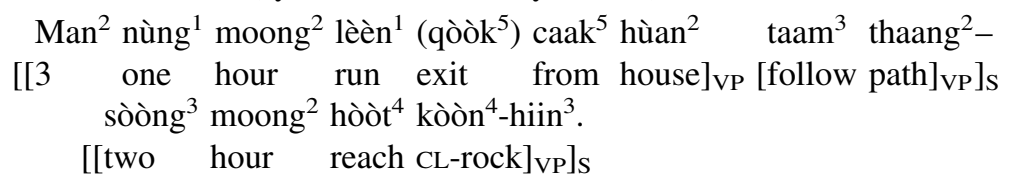

'At one he ran, exited from the house, followed the path, (and) at two he reached the rock.'

These intonation breaks also license separate negation of the VPs, showing that 22 is structurally different from 21. Example 21 is monoclausal and has the MEP, while 22 is multiclausal and lacks the MEP.

Type-II languages have macro-event expressions that may combine a departure and an arrival event, but may or may not require a separate macro-event expression for the encoding of passing events, depending on the type of the passing event. The fact that route-path functions are less likely crosslinguistically to be expressed (at the same level of differentiation) in the ground phrase compared to bounded-path functions (in line with the markedness considerations of Clark 1973; see also Creissels 2006 and Nikitina 2006) has the somewhat counterintuitive consequence that departure and arrival subevents are more easily integrated in macro-event expressions than passing subevents, which temporally lie between them. ${ }^{20}$ Consider the case of Japanese. Japanese is a

\footnotetext{
${ }^{20}$ This does not, of course, mean that the denotation of motion macro-event expressions in type-II languages is somehow discontinuous, or, conversely, that speakers of type-II languages consider motion events with route paths as discontinuous. As discussed in $\S \S 3$ and 7, the MEP is an interface property of constructions, not a property of semantic or conceptual event representations.
} 
verb-framed language on Talmy's (2000) typology of motion-event-lexicalization patterns. That is, path functions are primarily expressed in verbs, rather than in 'satellites' (verb particles) or ground-denoting phrases. But, as in Spanish and other Romance languages, source and goal functions are, in addition, also obligatorily distinguished in ground phrases-in 23 below, by the ablative case marker or postposition -kara and the 'extreme point' postposition -made 'until', which in this case bounds the path and thus effectively entails a goal function (Aske 1989, Beavers 2004). The source is expressed by an ablative-marked NP, which is headed by a relational noun possessed by the ground-denoting nominal in $23 .^{21}$

(23) (Kinoo) ki-no tokoro-kara ie-made it-ta. yesterday tree-GEN place-ABL house-until go-PAST

'[One] went from the tree to the house (yesterday).'

(Japanese)

Given a change-of-location verb that is semantically compatible with both source and goal specifications - such as $i k u$ 'go' - it becomes possible to combine a departureand an arrival-entailing ground phrase in a single VP. Since an optional time adverbial has to be understood as denoting a time interval that covers both subevents, the construction has the MEP.

Unlike source and goal, route-path functions cannot be expressed in Japanese without the use of a verb. The relevant class of verbs is described as 'ground-path verbs' in Muehleisen \& Imai 1996. Suppose the path from the tree to the house in 23 crosses a river. To add this passing subevent to the semantic representation expressed in 23 , the single-clause construction must be broken up into a main clause and a 'converb' clause (corresponding loosely to an English gerund clause; see Hasegawa 1996) headed by wataru 'cross.' As 24 shows, the resulting superordinate sentence no longer has the MEP.

(24) (San-ji-ni) ki-no tokoro-o shuppatsu-shi-te, (yo-ji-ni) three-o'clock-DAT tree-GEN place-ACC departure-do-CON four-o'clock-DAT kawa-o watat-te, (go-ji-ni) ie-ni tsui-ta. river-ACC cross-CON five-o'clock-DAT house-DAT arrive-PAST

'Leaving the tree (at three), crossing the river (at four), [one] arrived at the house (at five).'

(Japanese)

Since Japanese lacks serial or multiverb constructions of the kind that permit the combination of multiple location-change-denoting VPs into single clauses with the MEP in Ewe and Lao, the non-MEP complex sentence displayed in 24 is the most densely packaged solution to representing the motion event with the fully specified tree-riverhouse path.

It is nevertheless possible in Japanese to express departure, passing, and arrival in a single macro-event expression provided the entire description can make do with the ground-path verb lexicalizing the route-path function as the sole verb. This is the case if, and only if, source and goal of the path can be described in terms of locations the figure occupies at the beginning and end of the passing event - in other words, if source and goal are contiguous to the route traversed during the passing event. In a discussion

\footnotetext{
${ }^{21}$ A referee wonders whether the verbs that are compatible with both source and goal phrases in type-II languages are semantically general, underspecified for path functions. Not so. As illustrated in 25 , it is possible under certain conditions to combine path verbs with ground phrases encoding path functions not expressed by the verb. See Matsumoto 1996 for further discussion. The situation is fundamentally different in type-III languages, since ground phrases in these languages are path-neutral.
} 
of possible word meanings, Matsumoto (1996:269) refers to this constraint as the 'coextensiveness condition.' He illustrates with the examples in 25.

(25) a. \#Jon-wa Bei Burijji-o Paro Aruto-kara Bakurei-ni watat-ta. John-TOP Bay Bridge-ACC Palo Alto-ABL Berkeley-DAT cross-PAST

'John crossed the Bay Bridge from Palo Alto to Berkeley.' (Japanese)

b. Jon-wa Bei Burijji-o San Furanshisuko-kara Ookurando-ni John-TOP Bay Bridge-ACC San Francisco-ABL Oakland-DAT watat-ta. cross-PAST

'John crossed the Bay Bridge from San Francisco to Oakland.'

(Japanese)

Since the Bay Bridge connects San Francisco and Oakland, 25b is acceptable while 25a is not, even if John did indeed start out in Palo Alto before traveling through San Francisco, crossing the bridge, passing through Oakland, and ending up in Berkeley. A coextensive-route interpretation is not available for the meaning conveyed in 24 unless is it is possible to conceptualize the tree and house as immediately contiguous with the river. Assuming this is not the case, any expression of the semantic representation of 24 necessitates segmentation into at least two macro-event expressions.

Arrernte, Basque, Hindi, and Trumai show distributions similar to those described above for Japanese. In Basque and Hindi, some route-path functions may actually be expressed in ground phrases without the presence of a route-denoting verb, whereas the encoding of other types of route paths requires such verbs, as it does in Japanese independently of the type of route. Examples 26 and 27 illustrate the contrast between a single-VP strategy and a converb strategy in Basque with respect to one and the same type of route (cf. Ibarretxe-Antuñano 2004a, 2007a). Example 26 has the MEP, while 27 does not; so the crossing subevent can be singled out for timing in 27 , but not in $26 .{ }^{22}$

(26) Arrasate-tik Oinati-ra joan zen mendi-an zehar.

Arrasate-ABL Oñati-ALL go.PERF AUX.3sG mountain-LOC through

'(S)he went from Arrasate to Oñati across (over) the mountains.' (Basque)

(27) Atzo Arrasate-tik Oinati-ra joan zen mendi-ak yesterday Arrasate-ABL Oñati-ALL go.PERF AUX.3sG mountain.PL-ABS eguerdian zeharkatu-ta. nOon.LOC cross.PERF-CON

'Yesterday (s)he went from Arrasate to Oñati, crossing the mountains at noon.'

(Basque)

Example 28 illustrates a single-clause description comprising departure, passing, and arrival events in Hindi. Here, the route path is encoded by an oblique phrase in instrumental case. This is possible because the route is coextensive with the entire path from source to goal and thus does not add a new location-change-subevent event to what is expressed by the complex verb le jaa 'take.' In this respect, 28 is similar to the Japanese example $25 b$ above.

\footnotetext{
${ }^{22}$ Basque is a verb-final language with a focus position left-adjacent to the verb. While source- and goaldenoting NPs are preferred in preverbal positions, like core arguments, PPs such as the route-denoting PP in 26 appear postverbally unless they occupy the focus position (cf. Ibarretxe-Antuñano 2007a).
} 
(28) Kutta mããs $=$ ko nadii $=$ se peR tak us raaste $=$ se le gayaa. dog.NOM meat $=$ ACC creek $=$ ABL tree until that route $=$ INST take go.SG.M.PERF 'The dog took the meat from the creek to the tree along the road.' 23

(Hindi)

Since time adverbials cannot access any of the three subevents without accessing any of the other two, the construction in 28 has the MEP.

(29) *Kutta mããs $=$ ko nadii $=$ se caar baje us raaste $=$ se saath dog.NOM meat $=$ ACC creek $=$ ABL four o'clock that route $=$ INST seven baje peR tak le gayaa.

o'clock tree until take go.SG.M.PERF

Intended: 'The dog took the meat from the creek to the tree at seven along the road at four.'

If the route is not coextensive with the path, a converbial construction is required. In the case of 30, the converb form is the 'conjunct participle' in -kar.

(30) Voh ghar=se dukaan ho-kar daftar gayaa.

he.NOM home $=$ ABL store be-CON office(DAT) go.SG.M.PERF

'He went from home to the office via (being at) the store.'

(Hindi)

As 31 shows, this construction no longer has the MEP.

(31) Voh ghar=se, caar baje dukaan ho-kar, saath baje

he.NOM home $=$ ABL four o'clock store be-CONJ.PRT seven o'clock

daftar gayaa.

office(DAT) go.SG.M.PERF

'He went from home, via (being at) the store at four, to the office at seven.'

(Hindi)

Summarizing, the integration of passing subevents in type-II languages depends on at least two factors: first, is it possible to express the route-path function in the ground phrase without a route-denoting verb? This is the case with some, but not all, route paths in Basque, but applies only marginally to Hindi and not at all in Japanese. And second, is the route coextensive with the path, that is, contiguous to source and goal? If so, it may be possible to combine source and goal phrases with a route-denoting verb, as in the Japanese example $25 \mathrm{~b}$, or to refer to the route with a general instrumental phrase that is added to the VP describing motion from source to goal, as in the Hindi example 28.

All type-II languages in our corpus are 'double-marking' in the sense that they are verb-framed languages but in addition distinguish path functions in the ground phrase. ${ }^{24}$ It is entirely conceivable, however, that there are other kinds of type-II languages. For instance, there might be languages that have serial verb constructions integrating departure and arrival, but not passing subevents. One may also wonder whether there are languages that have macro-event expressions combining source and route, but not

\footnotetext{
${ }^{23}$ Some speakers prefer the compound postposition (-ke) dwaaraa instead of the instrumental case in $-s e$, to avoid double -se marking.

${ }^{24}$ In Japanese, manner-of-motion verbs can dominate ground phrases construed as spatial delimiters of motion events, for example, PPs headed by the postposition -made 'until'; see Beavers 2004 and Aske 1989 for similar Spanish examples. Basque permits combinations of manner verbs and path phrases more freely; but the expression of manner is relatively infrequent overall in motion-event descriptions (cf. IbarretxeAntuñano 2007a,b). Verb-framing is perhaps best considered the predominant, rather than the exclusive, strategy in Basque.
} 
goal, or route and goal, but not source functions. As far as we are aware, no such languages have been attested. ${ }^{25}$

Type-III languages require a separate VP for encoding each location-change subevent that involves a distinct ground. These are verb-framed languages that lack the kind of double-marking of path relations found in Basque, Japanese, or Hindi (or in Spanish and other Romance languages, for that matter); ${ }^{26}$ they express location change exclusively in verb roots or stems. At the same time, these languages lack Ewe- or Lao-style multiverb constructions that combine multiple location-change-denoting VPs into a single MEP construction. Consider 32, a Yukatek description of the ECOM clip B5. In this scene, the moving figure is a red circle. There are three grounds encoded in 32: a blue square, which marks the source; a green triangle, which defines the goal; and a brown houseshaped object, which is passed by in between (see Fig. 1).

(32) $\mathrm{Ba}^{\prime} \mathrm{l}=\mathrm{e}$ ', be'òora $=\mathrm{a}$ ' $\mathrm{t}$-inw $=\mathrm{il}-\mathrm{ah}=\mathrm{e}^{\prime}$, $[$ thing $=$ TOP $][$ now $=$ D1 $] \quad[$ PRV-A. $1=\operatorname{see}-\mathrm{CMP}($ в. $3 \mathrm{sG})=$ тOP $]$

hun-p'éel chan áasul ba'l

[one-CL.IN DIM blue thing

'But, now, I saw it, a little blue thing'

$$
\begin{aligned}
& \text { k-u = p'áat-al } \quad \mathrm{t}-\mathrm{u}=\text { xùul } \quad \mathrm{le}=\text { tu' }^{\prime} \quad \text { h-luk' } \\
& \text { IMPF-A. } 3=\text { await.ACAUS-INC LOC-A. } 3=\text { end DEF }=\text { where PRV-leave(B.3sG) } \\
& \text { le }=\text { chan ba'l chak }=o^{\prime}, \quad \mathrm{k}-\mathrm{u}=\text { bin } \quad \mathrm{u}=\text { balak' }^{\prime}=\mathrm{e}^{\prime} \text {, } \\
& \mathrm{DEF}=\text { DIM thing } \operatorname{red}(\text { в. } 3 \mathrm{sg})=\mathrm{D} 2 \text { ] }[\mathrm{IMPF}-\mathrm{A} .3=\text { go A.3 }=\text { roll }=\text { тоP] } \\
& \mathrm{k}-\mathrm{u}=\mathrm{ts}^{\prime} \mathrm{o}^{\prime} \mathrm{k}-\mathrm{ol}=\mathrm{e}^{\prime} \text {, } \\
& \text { [IMPF-A.3 }=\text { end-INC }=\text { TOP] }
\end{aligned}
$$

'the little thing that's red, it went rolling, and then'

$$
\begin{aligned}
& \mathrm{k}-\mathrm{u}=\text { máan } \quad \mathrm{y}=\mathrm{iknal} \text { hun-p'éel chan ba'l chak } \quad \mathrm{xan}=\mathrm{e}^{\prime} \text {, } \\
& \text { [IMPF-A.3 }=\text { pass A. } 3=\text { at one-CL.IN DIM thing } \operatorname{red}(\text { в. } 3 \mathrm{sg}) \text { also }=\text { TOP] } \\
& \text { 'it passes by a little thing that's also red' }
\end{aligned}
$$

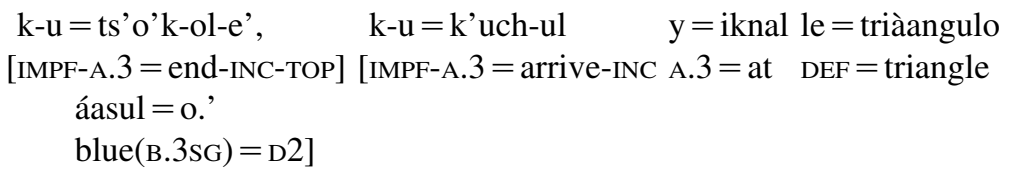

'and then it arrives at the blue ${ }^{27}$ triangle.'

(Yukatek)

\footnotetext{
${ }^{25}$ A referee suggests that this might be the consequence of a hypothetical implicational universal according to which only languages that express source and goal functions outside the verb also express route functions in this manner. We believe that this is a fruitful venue to explore in future research.

${ }^{26}$ Kilivila and Saliba use serial verb constructions to combine manner-of-motion and path verbs; as argued by Ameka and Essegbey (2001) and Zlatev and Yangklang (2004), this conforms neither to verb-framing nor to satellite-framing, but represents a separate type. However, unlike the other two serializing languages in our sample, Ewe and Lao, Kilivila and Saliba do not employ serial verb constructions to combine multiple location-change events into constructions that have the MEP; in this respect, they behave like purely verbframed languages. The same holds for Tzeltal, which Talmy (2000:65) characterizes as typologically 'split' on account of its use of path verb roots both in main verbs and in 'directional' satellites; again, directional constructions are not used-in our corpus - to integrate multiple location-change subevents in a single macroevent expression.

${ }^{27}$ The triangle is actually green. Yucatek, like many Mesoamerican languages, uses a single color term for 'grue', the category that includes both focal blue and focal green. The speaker here uses a loanword based on Spanish azul 'blue' synonymously with the autochthonous ya'x 'grue.'
} 
Clauses and topicalized phrases are tagged by brackets in 32. The three subevents of departing from the blue square, passing the house-shaped object, and reaching the triangle are reported in three distinct independent clauses. A more tightly packaged representation that entails the three subevents is not available in Yukatek. The presence of the topicalized phrase $k u=t s^{\prime} o^{\prime} k o l=e$ ', lit. 'it (having) ended', which functions as a sequentializer, shows that 32 does not have the MEP (the phrase is boldface in the translation).

This type of description is also found in Jalonke, Tzeltal, Yélî Dnye, and Zoogocho Zapotec. The Jalonke example (33) illustrates the tell-tale path-neutral ground phrases that are, along with the absence of multiverb constructions of the relevant kind, the key to this type of motion framing. Both the source ground (the tree) and the goal ground (the rock) are referred to by postpositional phrases headed by the same generic locative postposition $i$. Similarly, the relational noun iknal 'at' in Yukatek can be seen in 32 heading a route phrase as well as a goal phrase; it is likewise compatible with source or stationary locative interpretations - as is any other ground phrase in $\mathrm{Yu}$ katek. $^{28}$

(33) A keli wuri-n'ii', a siga (haa) geme-n'ii.'

3sG leave tree-DEF.LOC 3SG go until rock-DEF.LOC

'He left the tree, (and) went as far as the rock.'

(Jalonke)

Kilivila, Saliba, and Tidore are type-III languages as well. They differ from Tzeltal, Yélî, Yukatek, and Zapotec in that they do have Ewe/Lao-style multiverb constructions that combine multiple path-denoting phrases into single clauses under the MEP. But in contrast to Ewe and Lao, these languages lack multiverb constructions conflating departure and arrival events (let alone departure, arrival, and passing events). A Kilivila example is 34 .

(34) Kaukwau e-kaitau bunukwa e-la va vaya e-lupeli e-la va kai. [dog 3-carry pig $]_{S} \quad[3 \text {-go ITI creek }]_{S}[3 \text {-cross } 3 \text {-go ITI tree }]_{S}$ 'The dog carries pork, it goes to the creek, it crosses it, it goes to the tree.'

(Kilivila)

The units demarcated by brackets have clausal status on the negation criterion. Each of these units has the MEP.

Figure 2 summarizes the findings regarding the three segmentation types. Which type a language falls under is largely a matter of the interplay of two factors: (i) lexicalization - the expression of path or location-change functions in verbs, satellites, or ground phrases, or both; and (ii) the availability of certain morphosyntactic constructions. Ewe and Lao display basically the same motion-lexicalization patterns as type-III languages such as Yukatek or Yélî. They express location change (almost) exclusively in verbs. But they differ from type-III languages in that they have multiverb constructions combining multiple location-change-denoting verb phrases into single macro-event expressions. The double-marking strategy of the expression of path or location-change functions in type-II languages such as Basque, Japanese, and Hindi may be as much a matter of syntax as lexicalization, in that it depends on the ability of verb phrases

\footnotetext{
${ }^{28}$ A referee raises the question of whether it is possible for type-III languages to have at least one path function expressed outside the verb. Weak evidence to the effect that this is the case comes from Jalonke. As the example shows, goal phrases are optionally accompanied by the extent marker haa 'until', which semantically functions not unlike the postposition -made in the Japanese examples in 23, 24, and 49. Yet, it is still impossible to combine multiple path expressions in a single verb phrase; so Jalonke is still a typeIII language.
} 
to accommodate path-denoting expressions not subcategorized for by the verb (cf. Narasimhan 2003, Beavers et al. 2006).

Type I: one

\section{Departure Arrival Passing}

macro-event expression

Type II: one or two macro-event expressions, depending on type of passing event

Type III: three macro-event expressions
Dutch, Ewe, Lao, Marquesan, Tiriyó

FIgURE 2. The eighteen languages of Table 1 on the semantic typology of motion-event segmentation.

6. UNIVERSAL CONSTRAINTS ON FORM-TO-MEANING MAPPING IN MACRO-EVENT EXPRESSIONS. In $\S 5$, we focused on language-specific constraints on the encoding of locationchange sequences-constraints deriving from language-particular code, that is, the availability of lexical items and constructions. But our study also uncovered principles of form-to-meaning mapping that appear to be shared by all the languages in our sample, regardless of typological differences. We propose that these principles may be universals. What makes these particularly interesting is that they appear to be sensitive to the MEP, rather than to any construction or level of syntax per se. Consider the principle of biunique assignment of thematic relations originally proposed as a central tenet of Fillmore's 1968 case grammar (more recent formulations include Bresnan's 1980 'biuniqueness condition' and Chomsky's 1981 'theta-criterion'; see also Jackendoff 1990:59-70). Informally speaking, the BIUNIQUENESS CONSTRAINT requires every syntactic argument and oblique to be assigned exactly one thematic role by the lexical head of the verb phrase (and/or an argument structure construction in the sense of Goldberg 1995), and, conversely, every thematic role entailed by the lexical head or construction to be linked to exactly one argument or oblique. Path phrases in motionevent descriptions obey this principle as well.

(35) a. The ball rolls from the rock across the tracks to the hills.

b. 'The ball rolls from the rock across the tracks past the lake over the hills past the tree...

c. *The ball rolls from the rock ... to the hills to the hole.

d. *The ball rolls from the rock across the tracks from the lake...

A macro-event expression of English - a VP, that is - can encode maximally a source, a goal, and a route (cf. §5). Examples 35c and d are ill-formed on account of assigning the goal and source role, respectively, more than once, and $35 \mathrm{~b}$ seems at least problematic due to its multiple route phrases (see n. 19). These are violations of form-tomeaning mapping; whether any satellites or prepositions are used multiple times is immaterial. Thus, 36 shows the same violation of unique assignment of the source role 
as does $35 \mathrm{~d}$, and 37 shares with $35 \mathrm{c}$ the violation of unique assignment of the goal role. $^{29}$

(36) *Sally walked out of the house from the porch to the fence.

(37) *Sally went to Nijmegen home. ${ }^{30}$

The biuniqueness constraint does not apply to expressions that lack the MEP. For instance, 35-37 may be 'fixed' just by introducing coordination (compare §3).

$\left(36^{\prime}\right)$ Sally walked out of the house and (then) from the porch to the fence.

(37') Sally went to Nijmegen and (then) home.

The possibility of inserting the adverb then indicates that the constructions in $36^{\prime}-37^{\prime}$ lack the MEP. In Japanese, single-verb clauses obey biunique mapping, but converb constructions, which lack the MEP (cf. 24 above), do not. Hence, multiple goal assignment is rejected in $38 \mathrm{a}$, but not in $38 \mathrm{~b}$.

(38) a. *Ie-ni gakkoo-ni it-ta.

house-DAT school-DAT go-PAST

Intended: '(One) went to the house to school.'

(Japanese)

b. Ie-ni it-te gakkoo-ni it-ta.

[house-DAT go-CON]s [school-DAT go-PAST $]_{S}$

'Having gone to the house, (one) went to school.'

(Japanese)

Recall that Ewe has two monoclausal multiverb constructions, the more complex of which (i.e. the construction involving directional particles) lacks the MEP. As predicted, the simpler construction obeys biunique mapping, unlike the more complex one. Thus, 39, which has the MEP, is anomalous due to the goal role being assigned multiple times, whereas 40, which differs from 39 in the presence of the particle vá and thus lacks the MEP, is fine with multiple goal roles.

(39) "? Kofi vá afí sia gé dé afé-á me.

[Kofi come place this $]_{\mathrm{VP}}$ [drop ALL house-DEF in $]_{\mathrm{VP}}$

'Kofi came here, entered the house.'

(Ewe)

(40) Kofi vá afí sia vá gé đé afé-á me.

[Kofi come place this $]_{\mathrm{VP}}$ [VEN drop ALL house-DEF in $]_{\mathrm{VP}}$

'Kofi came here, entered the house.'

(Ewe)

Thus, what predicts biunique mapping is the MEP, not VP-hood or clausehood.

Why would the assignment of thematic relations be sensitive to the MEP? Event representations are individuated (aside from the factors mentioned in $\S 3$ ) by thematic relations (Carlson 1998). Compare a group reading under which a multitude of agents perform an action collectively with a 'pluractional' reading under which there is a multitude of actions, each performed by a different agent. The difference is in whether the agent role is assigned to a single collective referent or whether it is assigned to different referents with different instances of the event variable. Under the first reading, $41 \mathrm{a}$ is synonymous with $41 \mathrm{~b}$, whereas under the second, $41 \mathrm{a}$ means the same as $41 \mathrm{c}$.

\footnotetext{
${ }^{29}$ None of the path functions in 35-37 are assigned lexically, as none of the verbs are of the path-conflating type. That such motion descriptions nevertheless obey biunique role assignment seems to support the construction grammar analysis of English path phrases advocated in Goldberg 1995, Goldberg \& Jackendoff 2004, and Narasimhan 2003.

${ }^{30}$ Sally went home to Nijmegen is of course fine, but has to Nijmegen as an adjunct modifying (or in an appositive relation with) home, so the goal role is assigned only once.
} 
(41) a. Sally and Floyd bought a piano.

b. Sally and Floyd bought a piano together.

c. Sally bought a piano and Floyd bought a piano.

Consequently, a construction that represents an event as a single unitary whole with a unique beginning, end, duration, and position in time-in other words, a construction that has the MEP — cannot assign any thematic relation to more than one (potentially collective) referent.

Two further principles, with similar rationales to the biuniqueness constraint, are the MACRO-EVENT LINKING PRINCIPLE and the REFERENTIAL UNIQUENESS CONSTRAINT. Event descriptions encode sets of subevents and sets of relations that hold among thesetemporal relations, causal relations, and so on. According to the macro-event linking principle, the only subevents that may be referred to in a macro-event expression are those subevents to which the (temporal, causal, etc.) relations encoded by the expression are understood to apply. Consider the triads in 42-43.

(42) a. Sally walked past the barn to the mill.

b. Sally walked to the mill past the barn.

c. Sally walked to the mill and later passed the barn.

(43) a. Sally walked out of the house into the garden.

b. Sally walked into the garden out of the house.

c. Sally walked into the garden and later left the house.

The macro-event expressions in $42 \mathrm{~b}$ and $43 \mathrm{~b}$ mean the same as those in $42 \mathrm{a}$ and $43 \mathrm{a}$, respectively. The order of the path phrases is irrelevant to this interpretation. It is impossible to interpret the passing subevent in $42 \mathrm{~b}$ as following the arrival subevent. To obtain this order, the description must be broken up into two macro-event expressions, as in 42c. Similarly, the arrival subevent in $43 \mathrm{~b}$ cannot be understood to precede the departure subevent, unlike in $43 \mathrm{c}$, since motion macro-event expressions can refer to subevents of departure, passing, and arrival if they follow each other in this order. A Japanese example is given in 44 .

(44) a. Ki-no tokoro-kara ie-made it-ta. tree-GEN place-ABL house-until go-PAST

'(Someone) went from the tree to the house.' (Japanese)

b. Ie-made ki-no tokoro-kara it-ta.

house-until tree-GEN place-ABL go-PAST

'To the house (someone) went from the tree.'

(Japanese)

These are macro-event expressions as demonstrated in 23-24 above. The fronting of the goal phrase in $44 \mathrm{~b}$ puts the fact that the house was the goal of the motion event in focus, but does not change the interpretation otherwise. To obtain the reading that the house was reached before the departure from the tree, the description must be broken up into two macro-event expressions, as in 45.

(45) Yoogisha-wa sono hi-no gogo ie-made iki, sono suspect-TOP that day-GEN afternoon house-until go that yokujitsu ki-no tokoro-kara eki-made it-ta. following.day tree-GEN place-ABL station-until go-PAST

'The suspect went to the house in the afternoon on that day, and on the following day, went from the tree to the station.'

(Japanese)

We use the familiar Ewe constructions to demonstrate that the macro-event linking principle is specifically sensitive to the MEP. The simple multiverb construction in $46 \mathrm{a}$ 
has the MEP. A permutation of the path-denoting expressions in this construction results in anomaly; for some speakers, $46 \mathrm{~b}$ is unacceptable. To obtain the reverse-order interpretation, a directional particle such as 'itive' hé in $46 \mathrm{c}$ is required, lifting the MEP. ${ }^{31}$

(46) a. Sally zo tó kpó-á yú yi gaté-á gbó.

[Sally walk pass barn-DEF skin $]_{\mathrm{VP}}$ [go mill-DEF place $]_{\mathrm{VP}}$

'Sally walked, passed the barn, (went) to the mill.'

(Ewe)

b. 'Sally zo yi gaté-á gbó tó kpó-á yú.

[Sally walk go mill-DEF place $]_{\mathrm{VP}}$ [pass barn-DEF skin $]_{\mathrm{VP}}$

'Sally walked, (went) to the mill, passed the barn.'

c. Sally zo yi gaté-á gbó hé-vá tó kpó-á yú.

[Sally walk go mill-DEF place $]_{\mathrm{VP}}$ [ITI-come pass barn-DEF skin $]_{\mathrm{VP}}$

'Sally walked, (went) to the mill, passed the barn.'

(Ewe)

The referential uniqueness constraint concerns referential binding in macro-event expressions. It appears to be universally impossible to refer to the same ground more than once in the same macro-event expression, even if the reference is under different thematic relations (here, path functions).

(47) a. *Floyd went from [the tree $]_{\mathrm{i}}$ to $[\text { the tree }]_{\mathrm{i}} / \mathrm{it}_{\mathrm{i}}$.

b. Floyd went from the first tree to the second (tree).

c. Floyd went away from [the tree $]_{\mathrm{i}}$ and back to $\mathrm{it}_{\mathrm{i}}$.

(48) a. *Sally went out of [the tunnel $]_{\mathrm{i}}$ in(to [the tunnel $]_{\mathrm{i}} / \mathrm{it}_{\mathrm{i}}$ ).

b. Sally went out of the first tunnel into the second (tunnel).

c. Sally went out of the tunnel and in (again).

The anomaly of $47 \mathrm{a}$ and $48 \mathrm{a}$ is caused by two path phrases referring to the same ground. As $47 \mathrm{~b}$ and $48 \mathrm{~b}$ show, coreference is the only wellformedness violation here. The problem disappears when the ground-denoting phrases are referentially disjoint. In order to refer to the same ground twice, under different path functions, multi-macro-event expressions such as those in $47 \mathrm{c}$ and $48 \mathrm{c}$ are required. Example 49 illustrates the same points for Japanese.

(49) a. *Hanako-wa ki-no $\mathrm{i}_{\mathrm{i}}$ kotoro-kara sono $\mathrm{ki}^{-\mathrm{no}_{\mathrm{i}}}$ tokoro-made it-ta. Hanako-TOP tree-GEN place-ABL that tree-GEN place-until go-PAST

Intended: 'Hanako went from the tree to that (same) tree.' (Japanese)

b. Hanako-wa ip-pon-me-no ki-no kotoro-kara

Hanako-TOP one-CL-ORD-GEN tree-GEN place-ABL ni-hon-me-no ki-no tokoro-made it-ta. tWo-CL-ORD-GEN tree-GEN place-until go-PAST

'Hanako went from the first tree to the second tree.'

c. Hanako-wa ki-no ${ }_{i}$ kotoro-kara ie-no hoogaku-e

Hanako-TOP tree-GEN place-ABL house-GEN direction-ALL shuppatsu-shi, ichi-jikan-go-ni sono ki-no departure-do one-hour-later-DAT that tree-GEN tokoro-made modot-ta.

place-until return-PAST

'Hanako departed from the tree to the direction of the house, and one hour later, returned to the tree.'

(Japanese)

\footnotetext{
${ }^{31}$ This means that serial or multiverb constructions that obey a principle of iconic interpretation, as proposed by Tai (1985), by hypothesis lack the MEP. However, iconic interpretation must not be confused with iconic ordering of verb phrases in serial or multiverb constructions, as examined in, for example, Good 2003. Only a construction in which the order of VPs can actually be reversed, with such a reversal yielding a concomitant reversal in temporal interpretation, can be said to have a semantics governed by iconicity.
} 
Ewe examples illustrate the sensitivity of the referential uniqueness constraint to the MEP, as opposed to any level of syntax.

(50) a. *Floyd dzó le atí-á gbó tró yi é-gbó.

[Floyd leave LOC tree-DEF place $]_{\mathrm{VP}}[\text { return go 3sG-place }]_{\mathrm{VP}}$

Intended: 'Floyd left the tree, returned (went) to the tree.'

(Ewe)

b. Floyd dzó le atí gbắto gbó yi evelíá gbó.

[Floyd leave LOC tree first place $]_{\mathrm{VP}}$ [go second place $]_{\mathrm{VP}}$

'Floyd left the first tree, went to the second.'

(Ewe)

c. Floyd dzó le atí-á gbó hé-ga-tró yi é-gbó.

$[\text { Floyd leave LOC tree-DEF place }]_{\mathrm{VP}}$ [ITI-REP-return go 3sG-place $]_{\mathrm{VP}}$

'Floyd left the tree, returned (went) to the tree.'

(Ewe)

The simple multiverb construction that has the MEP does not permit multiple references to the same tree as ground (50a), whereas such references are fine in the multiverb construction with the 'itive' directional particle hé in 50c, which lacks the MEP. Yet both constructions constitute single clauses composed out of two verb phrases each.

The apparent NP binding constraints in these examples are reminiscent of binding regularities in core-argument configurations, where coreferent objects in many languages require some form of reflexive marking (see for example Chomsky 1981, Levinson 1987, Reinhart 1983). Indeed, one key difference is the apparent lack of (an equivalent of some kind of) reflexive marking in path phrases (e.g. a morpheme in the goal phrase of $47 \mathrm{a}, 48 \mathrm{a}, 49 \mathrm{a}$, or $50 \mathrm{a}$ that indicates that the goal ground is coreferent with the source ground of these sentences) — to the best of our knowledge, such marking is unattested in the languages of the world. Jackendoff (1990:64-68) presents an account of NP binding in terms of form-to-meaning mapping regularities. It may be possible to extend such an approach to cover binding phenomena in path phrases as well. ${ }^{32}$

While the three principles discussed so far affect the form-to-meaning mapping in macro-event expressions beyond the motion domain (or, in the case of the referential uniqueness constraint, appear to be a special case of such a more general principle), we have also found evidence of one domain-specific principle. This UNIQUE VECTOR CONSTRAINT concerns specifically the encoding of direction information in macro-event expressions. Directions (in the technical sense of Jackendoff 1983; cf. Table 1 above) are the only path functions that are not restricted to (literal or metaphorical) motion events, but also define locations in spatial frames of reference (Levinson 1996) and orientations. Directions may be represented as vectors whose head and tail coordinates are places - for example, the places occupied by figure and ground during some stage of a motion event (e.g. Bohnemeyer 2003). The unique vector constraint is discussed in detail in Bohnemeyer 2003; we provide a brief summary in the following. Consider the examples in 51 in relation to Figures 3-4.

(51) a. Floyd went away from A toward B.

b. Floyd went away from A and then toward B.

Example 51a is a good description of the scenario in Fig. 3, but does not adequately describe the one depicted in Fig. 4. Conversely, 51b is compatible with Fig. 4, but not

\footnotetext{
${ }^{32}$ We owe the discovery of both the macro-event linking principle and the referential uniqueness constraint to an example pointed out by our colleague Bhuvana Narasimhan during a discussion of the unique vector constraint (see below): *It went into the tunnel out. Subsequent analysis indicated that the apparent anomaly of this sentence is the result of the violation of two principles, namely, the ones proposed here. We then tested the proposed constraints in the languages of our sample with examples such as those in 41-50, and found them to hold without exceptions.
} 


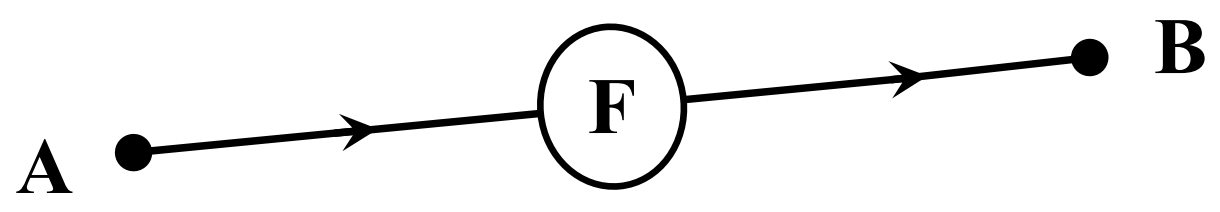

FIGURE 3. Scenario instantiating 51a.

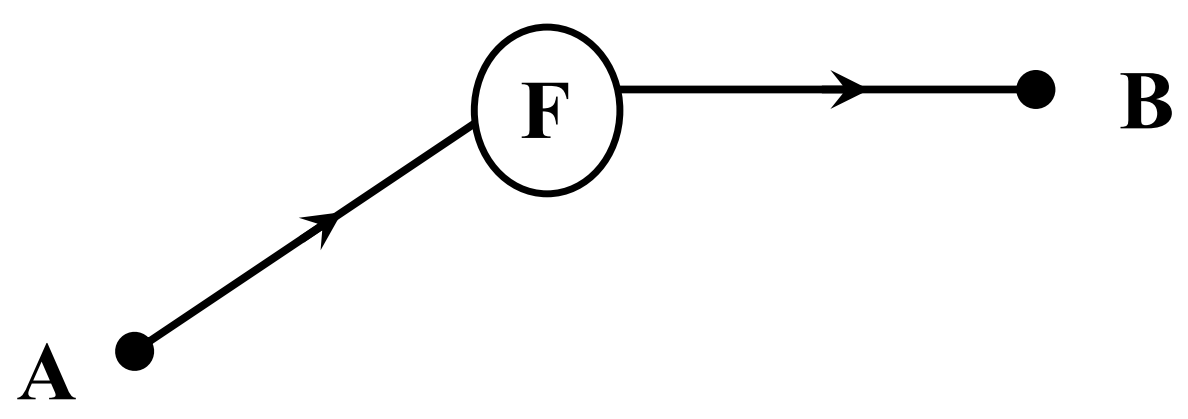

FIGURE 4. Scenario instantiating $51 \mathrm{~b}$.

with Fig. $3 .{ }^{33}$ In the framework of Jackendoff 1983, the two direction specifications in 51a are assumed to have different path functions, termed AWAY-FROM and TOWARD. As 51a shows, a macro-event expression in English is compatible with direction adverbials in these two functions as long as they encode collinear direction vectors. This does not adequately describe a scenario involving direction change, such as that in Fig. 4. According to the unique vector constraint, two noncollinear direction vectors cannot be encoded in the same macro-event expression. Put differently, the constraint requires that if a macro-event expression includes more than one direction specification, then the two or more specifications must refer to the same direction. ${ }^{34}$

The unique vector constraint has consequences for the encoding of motion events that involve direction change. Either the direction-change information is not explicitly encoded (and possibly derived by implicature), or the description is segmented into multiple macro-event expressions - one per direction vector. Consider Figure 5, a frame from the stimulus item ECOM C6. Example 52 is an English description of this clip.

(52) a. The red circle rolls to the right inside a blue u-shaped object, ...

b. ... climbs up on the inside wall of the blue object, ...

\footnotetext{
${ }^{33}$ The description in $51 \mathrm{~b}$ is compatible with Fig. 3 under psychological assumptions, for example, as a statement of the figure's intentions or the stream of consciousness of an observer. The main point here is that $51 \mathrm{a}$ is strictly incompatible with Fig. 4.

${ }^{34}$ One could attempt to do away with the unique vector constraint and derive the regularity instead from the principle of biunique assignment of thematic relations. This would require abandoning Jackendoff's distinction between the TOWARD and AWAY-FROM path functions in favor of a single direction function. That multiple direction specifications within the same macro-event expression must refer to the same direction would then be explained by their bearing some direct syntactic relation (one modifying the other or the two being in an appositive relation) and thus jointly receiving a single direction function. An apparent problem is that multiple TOWARD phrases or multiple AWAY-FROM phrases in the same macro-event expression can violate biunique mapping even if the two direction specifications denote collinear vectors (e.g. *Floyd walked toward the tree toward the well), suggesting that the TOWARD and AWAY-FROM functions are distinct.
} 

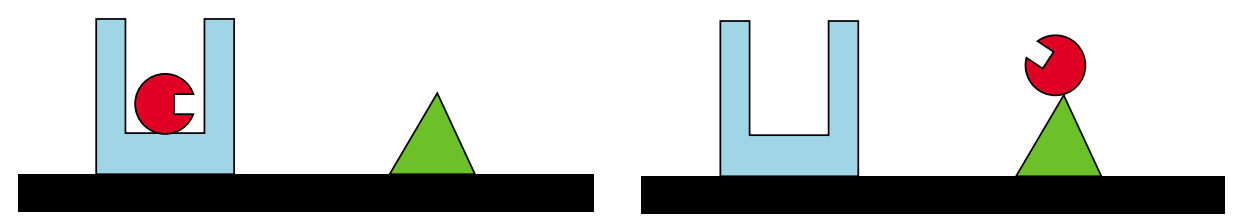

FIGURE 5. First and last frame of ECOM C6.

c. ... rolls out over the top ...

d. ... and down again on the outside wall until it hits the ground, ...

e. ... then rolls on until it reaches a green triangle, ...

f. .... and finally rolls up the triangle to the top.

The description in 52 is segmented into six macro-event expressions, one per direction vector. Descriptions of this clip adhered to this format in all languages in our sample, except for frequent omissions of some of the segments. The Ewe description in 53 omits two segments, the initial move to the right inside the u-shaped object and the move out over the top, and merges two other segments - the motion down and the motion right to the triangle-representing it as a single direction vector.

(53)

Circle lá líá rectangle lá hé di tó anyígbá
[circle DEF climb rectangle $\left.{ }_{\mathrm{DEF}}\right]_{\mathrm{VP}}$ [ITI descend pass ground] yi da-lía triangle lá vá dó é-ta-me.

[go DIR-climb triangle DEF $]_{\mathrm{VP}}$ [VEN arrive 3sG-peak-in $]_{\mathrm{VP}}$

'The circle climbed the rectangle, descended passed the ground, climbed the triangle, came arriving at the top.'

(Ewe)

Example 53 features the more complex multiverb construction employing directional particles shown in $\$ 3$ to lack the MEP.

The unique vector constraint is directly related to an apparently universal gap in (spoken $)^{35}$ language code-the lack of direction change morphemes with meanings such as 'up and then left', or 'north and then east', and so on. In the absence of such morphemes, a representation distributing multiple directions over the time course of an event leads to clashes unless it is broken up into multiple segments, each mapping a single direction vector into a single subevent. We have not found evidence of directionchange morphemes in any of the languages in our sample. ${ }^{36}$ Whether this apparently universal absence is by accident or by design remains a matter of future research.

The four principles of macro-event encoding discussed in this section define universal constraints on the segmentation of motion events. They are 'centripetal' forces set against the 'centrifugal', diversity-inducing, effect of the typological differences discussed in the previous section. This combination of language-specific and universal

\footnotetext{
${ }^{35}$ Preliminary evidence from descriptions of our stimulus items in Dutch Sign Language collected by D. P. Wilkins suggest that the constraint may not obtain in signed languages since they allow for iconic representations of directions and direction changes.

${ }^{36}$ Possible exceptions are expressions meaning 'back' or 'return.' Bohnemeyer 2003 examines such expressions, concluding that they do not violate the unique vector constraint. Bohnemeyer 2003 also addresses a number of other apparent exceptions, for example, path shape expressions such as zigzag or circle.
} 
constraints raises important questions about the workings of the syntax-semantics interface, to which we now turn.

7. Summary and implications. We have presented elements of a semantic typology of motion-event encoding. Semantic typology is the study of linguistic categorization across languages. A semantic typology of event encoding necessitates a number of important methodological decisions. Since events are encoded in language, not just by lexical items alone, but by verb phrases, clauses, and larger discourse units, we have focused here on the problem of how conceptually comparable event representations are segmented across units of linguistic code. In view of the compositionality of linguistic event descriptions, a typology of event segmentation cannot result in an inventory of expressions. Consequently, our target has been specifically universal and languagespecific constraints on event segmentation. We have shown that syntactic categories such as verb phrases and clauses vary across languages in the packaging of event information, and that language-specific constructions such as serial verb or multiverb constructions may be used to convey the information that is encoded in verb phrases in other languages. To have a measure of event segmentation that can be applied crosslinguistically independently of the language-particular properties of syntactic constructions, we introduced the macro-event property (MEP). The MEP is a property of constructions that present the information about an event in such as way as to not permit temporal operators that scope into proper subevents. In other words, macroevent expressions (constructions that have the MEP) present an event in terms of a unique initial and/or terminal boundary, a unique duration, and a unique position on the time line. Our study thus specifically aimed to uncover constraints on the segmentation of complex event scenarios across macro-event expressions. We targeted the motion domain in view of its often presumed universality and the conceptual and technical advantages that come from having a direct spatial map of the time course of events and their breakpoints.

An examination of eighteen typologically and genetically diverse languages, using video stimuli and a questionnaire, has uncovered a surprising amount of variation in motion-event segmentation. This variation is driven by lexicalization differences and by differences in the availability of syntactic constructions. The languages in our sample fall into three types. Languages of the first type can integrate subevents of departure, passing, and arrival all in one macro-event expression. These languages are either satellite-framed on Talmy's $(1985,2000)$ lexicalization typology and thus permit multiple path phrases in a single verb phrase, or they have multiverb constructions that string multiple location-change-denoting VPs together to form macro-event expressions. Languages of the second type afford macro-event expressions that encode both departure and arrival, but commonly, though not necessarily, require a second macro-event expression for the integration of passing subevents. In our sample, all of these are languages that employ a double-marking strategy for the encoding of path functions, expressing them in verb roots (verb-framed) but simultaneously marking them in the ground phrase. The marking of path functions outside the verb root excludes route paths in these languages or only permits the encoding of certain kinds of route paths. The encoding of route-path functions commonly requires a second verb phrase. Languages of the third type isolate each location-change subevent of departure, passing, or arrival in a separate macro-event expression. These are languages that express path functions exclusively in verb roots. Consequently, path phrases are exclusively interpreted according to the roles assigned to them by a verb root, without any formal 
indication of the thematic relation on them. Hence, these languages do not permit more than one path phrase per verb. And lacking multiverb constructions that permit the combination of multiple such VPs into single macro-event expressions, each VP is projected into its own macro-event expression.

Talmy's typology of lexicalization patterns and semantic composition in complex event expressions does not directly deal with the problem of event segmentation. The nature of the interaction between Talmy's lexicalization patterns and our segmentation types is a nontrivial empirical finding of our study: lexicalization differences are one of the two driving forces behind the crosslinguistic variation in segmentation types; the effects of lexicalization patterns may be offset by syntactic properties such as the double-marking of path functions in the ground phrase in verb-framed languages and the availability of constructions that combine multiple location-change-denoting verbal projections into motion macro-event expressions. Our findings also highlight the importance of distinguishing between double-marking verb-framed languages and 'radically' verb-framed languages such as Yukatek which do not express path functions outside of verb roots at all; the significance of this distinction has hitherto eluded the scholars working within Talmy's framework.

While factors of lexicalization and the availability of constructions cause languages to differ in how many location-change subevents they can combine into single macroevent expressions, we also found evidence of a number of principles of form-to-meaning mapping at the syntax-semantics interface that appear to be shared across languages. This includes the principle of biunique assignment of thematic relations to arguments and obliques, which we have confirmed to extend to path functions as well. The macroevent linking principle restricts the subevents encoded in a macro-event expression according to the temporal and causal relations encoded by the expression. This ensures that the temporal interpretation of the subevents is independent of the order of path phrases, whether or not the latter mirrors the former iconically. The referential uniqueness constraint prohibits the referential coindexing of ground-denoting NPs in macroevent expressions; it appears to be akin to the better-studied principles governing NP binding in core-argument configurations. While these three principles are of a wider currency than the encoding of motion events, a fourth principle, the unique vector constraint, is specific to the motion domain. This principle requires all direction specifications in a macro-event expression to encode collinear direction vectors. Of particular interest from the point of view of linguistic theory is the finding that these four principles of form-to-meaning mapping appear to be sensitive to the MEP. This suggests that the MEP is not merely an otherwise arbitrary criterion that happens to be useful as a metric for a typology of event segmentation, but that it is an integral part of the language faculty-more specifically, the syntax-semantics interface.

The research presented here deals with constraints on the segmentation of motion descriptions in the sense of principles that limit the amount of information maximally 'packaged' in a macro-event expression. An important complementary question is that of preferred patterns of distribution of motion-event information in discourse. Future research must examine whether speakers of all languages that are able to combine certain kinds of subevents and path segments in motion macro-event expressions have the same preferences for doing so, or whether there is crosslinguistic variation in this respect as well, and if so, what factors drive this variation.

We now raise two broad implications of our study. First, to what extent are the stunning crosslinguistic differences in how much information about a motion event can be encoded in a macro-event expression indicative of (if not causal factors in) variation 
in the conceptual encoding of motion events? And second, how are the interfaces among syntax, semantics, and nonlinguistic cognition designed given that they are flexible enough to accommodate this amount of crosslinguistic variation? Consider what from an English perspective appears to be a conceptually simple event of motion from source past some route ground to goal, as in Fig. 1. Japanese requires minimally two macroevent expressions to cover this scenario, and Yukatek speakers need three independent clauses, one per location-change subevent. Ewe and Lao, by contrast, require three VPs, just like Yukatek, but they combine these VPs into single macro-event expressions. Do these linguistic differences lead speakers to conceptualize the event differently? And what rules and mechanisms do speakers of these languages follow when they link the three path functions into one VP in English, two clauses in Japanese, three clauses in Yukatek, and three VPs in one clause in Ewe and Lao?

Following Jackendoff $(1983,1990,1997,2002)$, we assume the following: there is a system of conceptual representations - CONCEPTUAL STRUCTURE (CS) — designated to mediate between other systems of internal cognition and language; SYNTACTIC STRUCTURE (SS) is associated with meaning through a direct mapping between SS and CS; ${ }^{37} \mathrm{CS}$, like SS, is a generative system of representation (with an expressive power equal to or greater than that of SS); the mapping between CS and SS is governed by formto-meaning mapping principles (correspondence rules in Jackendoff's parlance); and CS plays an important role in nonlinguistic reasoning, but has no monopoly over other cognitive faculties in this regard.

Are speakers of languages that differ in their constraints on event segmentation likely to also think differently about the same events? Are, say, Yukatek speakers more inclined to think about the scenario in Fig. 1 as a sequence of three events, whereas English and Ewe speakers conceptualize it as a single event? This is an empirical question that awaits further research. ${ }^{38} \mathrm{We}$ want to address here a related question. Should we assume, within the framework sketched above, that the macro-event property is encoded at CS? In other words, does CS distinguish between macro-event and nonmacro-event representations? If so, the form-to-meaning mapping principles discussed in $\S 6$ might be mirrored by corresponding wellformedness rules on macro-event representations at CS. ${ }^{39}$ The issue of relativistic effects would then translate into the following question: are the same CS macro-event representations encoded by different syntactic structures in different languages, or do speakers of different languages entertain different, language-specific CS macro-event representations? The alternative is that the MEP is purely a matter of form-to-meaning mapping - that event representations of arbitrary size and complexity are not broken down into macro-event representations at CS, but mapped into language-specific macro-event expressions at the SS-CS interface.

\footnotetext{
37 'Direct' here means not mediated by a separate system of semantic representations. This position has been criticized for independent reasons by Bierwisch (1996), Levinson (1997), and Pinker (1989). Our assumption of direct CS encoding simplifies the argument; but we would like to point out that this assumption directly bears on the question, discussed below, of whether macro-event and non-macro-event expressions may map into the same CS representations.

${ }^{38}$ For example, the paradigm used to record the segmentation of the contents of video clips into 'meaningful units' in Newtson 1973 and Zacks \& Tversky 2001 might be applicable to a test of this question. Are speakers of type-III languages more likely than speakers of type-I languages to segment a video featuring motion from one place to another into multiple units?

${ }^{39}$ Nikanne 1990 has proposed wellformedness rules on CS structures that mandate unique assignment of predicate functions-including path functions-within event representations. These rules would thus 'anticipate' biunique mapping at the level of CS.
} 
While this second scenario does not eliminate the possibility of language-specific event representations at CS, it takes away any compelling reason to assume such effects within the framework of the present discussion.

While we cannot yet say conclusively whether the MEP is encoded at CS, we want to point out an important boundary condition to any answer to this question. If the MEP is encoded at CS, it follows, given the above assumptions, that the macro-event expression in 54a and the multi-macro-event expression in 54b map into different CS representations.

(54) a. The red circle went from the blue square past the brown house-shaped object to the green triangle.

b. The red circle left the blue square, went past the brown house-shaped object, and arrived at the green triangle.

There are two semantic differences between 54a and b. First, the two sentences differ in event structure and lexical aspect. That in 54a is a single accomplishment, whereas that in 54b is a sequence of three achievements. And second, 54a entails that the time course of the event maps directly onto a single contiguous path connecting the three grounds in the order source-route-goal, whereas 54b merely implicates this. These differences could be accounted for either in terms of mappings into different CS representations or in terms of differences in the mapping between SS and CS. (A third possibility, which we do not pursue here further, is that the difference is encoded in a semantic representation intermediate between SS and CS, contrary to the assumption of direct CS encoding.) However, in order to pragmatically implicate in 54b what is semantically encoded in $54 \mathrm{a}$, the speaker uttering $54 \mathrm{~b}$ must in some sense have the scenario encoded in 54a 'in mind', in the sense of Grice's 1989 'meaning ${ }_{n n}$ ', and the hearer must infer that the speaker has this in mind in order to recover the implicated meaning. Pending further advances in the integration of pragmatics into the framework sketched above, we tentatively conclude that 54a and b map into the same CS representation, and that the semantic differences between them are differences in SS-CS mapping. This suggests that the MEP is not encoded at CS. Consequently we see no reason, at present, to assume that the crosslinguistic differences in event segmentation uncovered here induce differences in conceptual event representations.

If the MEP is not encoded at CS, it follows that event representations of arbitrary size and complexity are mapped into language-specific macro-event expressions at the SS-CS interface. The simplest set of assumptions about the design of the CS-SS interface that is compatible with this hypothesis and the findings reported in the previous sections is this: speakers have procedural knowledge of which constructions in their native languages have the MEP. On an account such as that proposed in Goldberg 1995 and Goldberg \& Jackendoff 2004, this property may be mentally stored with the construction template; but exceptions such as those discussed in $§ 3$ (e.g. example 14) suggest that speakers are also able to compute on-line whether a construction has the MEP. Furthermore, speakers have procedural knowledge of form-to-meaning mapping principles such as those discussed in $\S 6$, principles that make reference to the MEP. When encoding a CS event representation in SS, they single out the macro-event expressions and check for consistency with the form-to-meaning mapping principles. They can also directly target macro-event expressions if they wish to provide the most densely packaged linguistic representations available in their native language for their intended meanings. These processes should run equally efficiently regardless of the languagespecific properties of the constructions used. Future research must examine whether 
knowledge of the MEP (as such, as opposed to knowledge that a given construction has the MEP) and the form-to-meaning mapping principles that refer to it is innate or acquired, and if the latter, whether it has evolved as 'user-friendly' design that is grasped easily by children due to its intuitiveness.

\section{APPENDix A: EvEnT INTEGRATION QUESTIONNAIRE SCENARIOS.}

The selection of scenarios from the Event Representation Questionnaire (Bohnemeyer 1999) used in this study are given below (the final two scenarios were added in 2002).

SCENARIO METALANGUAGE REPRESENTATION

a1 GO (THEME, SOURCE, GOAL)

a2

GO (THEME, PATH, GOAL)

a3

GO (THEME, PATH, DIRECTION)

a4

GO (THEME, SOURCE, PATH, GOAL)
EXAMPLES

She went from the tree to the rock.

He went from Nijmegen to Arnhem.

She went out of the house into the garden.

He went along the river to the bridge.

She went via Elst to Arnhem.

He went across the street into the store.

She went along the road towards the hill.

He went through the tunnel away from the station.

She went north through the valley.

He went from Nijmegen via Elst to Arnhem.

She went out of the kitchen across the back porch into the garden.

He went from the river over the hill to the forest.

She went out of the garage towards the gate.

He went from Nijmegen towards Arnhem.

She went off the reservation heading north.

He went from the farm along the ditch.

She went out of the station through the tunnel.

He went from Nijmegen past Elst.

APPENDIX B: ECOM CLIPS.

A description of the selection of ECOM clips (Bohnemeyer \& Caelen 1999) used in the study is given below.

CLIP DESCRIPTION

B1 Red circle rolls to green triangle.

B2 Red circle rolls over yellow bar to green triangle.

B3 Red circle rolls over yellow bar to green triangle, passing a brown house-shaped object along the way.

B4 Red circle rolls from blue square over yellow bar to green triangle.

B5 Red circle rolls from blue square over yellow bar to green triangle, passing a brown house-shaped object along the way.

C1 Red circle inside U-shaped container rolls to wall of container.

C2 Red circle inside U-shaped container rolls to wall of container and up the wall.

C3 Red circle inside U-shaped container rolls to wall of container, up the wall, and onto the top of the wall.

C4 Red circle inside U-shaped container rolls to wall of container, up the wall, onto the top of the wall, and down on the outside of the container.

C5 Red circle inside U-shaped container rolls to wall of container, up the wall, onto the top of the wall, down on the outside of the container, and on away from the container to a green triangle.

C6 Red circle inside U-shaped container rolls to wall of container, up the wall, onto the top of the wall, down on the outside of the container, away from the container to a green triangle, and finally up the side of the triangle to the top.

\section{REFERENCES}

Авон, Enoch O.; Felix K. Ameka; and James Essegbey. 2007. Moving from verbs to prepositions in Gbe (West Africa). Variation and change in adpositions of movement, ed. by Hubert Cuykens, Walter De Mulder, and Michel Goyens. Amsterdam: John Benjamins, to appear. 
AMEKA, Felix K. 1991. Ewe: Its grammatical constructions and illocutionary devices. Canberra: Australian National University dissertation.

Ameka, Felix K. 2003. Prepositions and postpositions in Ewe (Gbe): Empirical and theoretical considerations. Typologie des langues d'Afrique et universaux de la grammaire, vol. 2: Benue-Kwa, Soninke, Wolof, ed. by Anne Zribi-Hertz and Patrick Sauzet, 41-67. Paris: L'Harmattan.

AмeKA, Felix K. 2005a. Ewe serial verb constructions in their grammatical context. Serial verb constructions: A cross-linguistic typology, ed. by Alexandra Y. Aikhenvald and R. M. W. Dixon, 124-43. Oxford: Oxford University Press.

AMEKA, Felix K. 2005b. Multiverb constructions on the West African littoral: Micro-variation and areal typology. Grammar and beyond: Essays in honor of Lars Hellan, ed. by Mila Vulchanova and Tor A. Åfarli, 15-42. Oslo: Novus.

Ameka, Felix K., and James Essegbey. 2001. The expression of complex translational motion events in three verb-serializing languages. Annual report 2001, ed. by Ann Kelly and Alissa Melinger, 94-97. Nijmegen: Max Planck Institute for Psycholinguistics.

Ameka, Felix K., and James Essegbey. 2006. Elements of Ewe grammar of space. In Levinson \& Wilkins, 362-402.

Ansre, Gilbert. 1966. The grammatical units of Ewe: A study of their structure, classes, and systems. London: University of London dissertation.

Aske, Jon. 1989. Path predicates in English and Spanish: A closer look. Berkeley Linguistics Society 15.1-14.

BAKer, MARK C. 1989. Object sharing and projection in serial verb constructions. Linguistic Inquiry 20.513-53.

BeAvers, John. 2004. On the nature of goal markers and event delimiters: Evidence from Japanese. Stanford, CA: Stanford University, MS.

Beavers, John; Beth Levin; and Shiao Wei Tham. 2006. The typology of motion events revisited. Paper presented at the 80th annual meeting of the Linguistic Society of America, Albuquerque, NM, January.

Berlin, Brent; Denise A. Breedlove; and Peter H. Raven. 1974. Principles of Tzeltal plant classification. New York: Academic Press.

Berlin, Brent, and Paul Kay. 1969. Basic color terms. Berkeley: University of California Press.

Bierwisch, MANFred. 1996. How much space gets into language? Language and space, ed. by Paul Bloom, Mary A. Peterson, Lynn Nadel, and Merrill F. Garrett, 31-76. Cambridge, MA: MIT Press.

BoAs, Franz. 1911. Linguistics and ethnology. Handbook of American Indian languages (BAE-B 40, part 1), ed. by Franz Boas, 59-73. Washington, DC: Smithsonian Institution.

BoHNEMEYER, JÜRGEN. 1999. A questionnaire on event integration. 'Manual' for the 1999 field season, ed. by David P. Wilkins, 87-95. Nijmegen: Max Planck Institute for Psycholinguistics.

BOHNEMEYER, JÜRGEN. 2003. The unique vector constraint. Representing direction in language and space, ed. by Emile van der Zee and Jon Slack, 86-110. Oxford: Oxford University Press.

BOHNEMEYER, JÜRGEN. 2008. The language-specificity of conceptual structure: Path, fictive motion, and time relations. Words and the world, ed. by Barbara Malt and Philip Wolff. Oxford: Oxford University Press, to appear.

Bohnemeyer, Jürgen, and Martiun CAelen. 1999. The ECOM clips: A stimulus for the linguistic coding of event complexity. 'Manual' for the 1999 field season, ed. by David P. Wilkins, 74-86. Nijmegen: Max Planck Institute for Psycholinguistics.

Bohnemeyer, Jürgen; Nicholas J. Enfield; James Essegbey; and Sotaro Kita. 2008. The macro-event property: The segmentation of causal chains. Event representation in language and cognition, ed. by Jürgen Bohnemeyer and Eric Pederson. Cambridge: Cambridge University Press, to appear.

Bresnan, Joan. 1980. Polyadicity. Lexical grammar, ed. by Teun Hoekstra, Harry van der Hulst, and Michael Moortgat, 97-121. Dordrecht: Foris.

Brown, Roger, and Eric H. LenNeberg. 1954. A study in language and cognition. Journal of Abnormal Social Psychology 49.454-62.

CABlitz, Gaby. 2002. Marquesan: A grammar of space. Kiel: University of Kiel dissertation. 
CARlson, Greg N. 1977. Reference to kinds in English. Amherst: University of Massachusetts, Amherst dissertation

Carlson, Greg N. 1998. Thematic roles and the individuation of events. Events and grammar, ed. by Susan Rothstein, 35-52. Dordrecht: Kluwer.

Casati, Roberto, and Achille C. VArzi. 1999. Parts and places: The structures of spatial representation. Cambridge, MA: MIT Press.

Chafe, Wallace. 1977. The recall and verbalization of past experience. Current issues in linguistic theory, ed. by Roger Cole, 215-46. Bloomington: Indiana University Press.

Chafe, Wallace. 1979. The flow of thought and the flow of language. Syntax and semantics, vol. 12: Discourse and syntax, ed. by Talmy Givón, 159-81. New York: Academic Press.

Chomsky, NoAm. 1981. Lectures on government and binding. Dordrecht: Foris.

Clark, Herbert H. 1973. Space, time, semantics, and the child. Cognitive development and the acquisition of language, ed. by Timothy E. Moore, 27-63. New York: Academic Press.

Creissels, Denis. 2006. Encoding the distinction between location, source, and destination: A typological study. Space in languages: Linguistic systems and cognitive categories, ed. by Maya Hickmann and Stéphane Robert, 19-28. Amsterdam: John Benjamins.

Davidson, DonAlD. 1967. The logical form of action sentences. The logic of decision and action, ed. by Nicholas Rescher, 81-95. Pittsburgh: University of Pittsburgh Press.

Dechaine, Rose-Marie. 1993. Serial verb constructions. Syntax: An international handbook of contemporary research, ed. by Joachim Jacobs, 789-825. Berlin: Mouton de Gruyter.

Dixon, R. M. W. 2006. Serial verb constructions: Conspectus and coda. Serial verb constructions: A cross-linguistic typology, ed. by Alexandra Y. Aikhenvald and R. M. W. Dixon, 338-50. Oxford: Oxford University Press.

Dowty, DAVID R. 1979. Word meaning and Montague grammar. Dordrecht: Kluwer.

EnField, Nicholas J. 2007. Verbs and multi-verb sequences in Lao. The Tai-Kadai languages, ed. by Anthony V. N. Diller. London: RoutledgeCurzon, to appear.

Fillmore, Charles J. 1968. The case for case. Universals of linguistic theory, ed. by Emmon Bach and Robert T. Harms, 1-90. New York: Holt, Rinehart, and Winston.

Fillmore, Charles J. 1972. Subjects, speakers and roles. Semantics of natural languages, ed. by Donald Davidson and Gilbert Harman, 1-24. Dordrecht: Reidel.

FodOr, JERry A. 1970. Three reasons not to derive 'kill' from 'cause to die.' Linguistic Inquiry 1.429-38.

Fu, Jingei; Thomas Roeper; and Hagit Borer. 2001. The VP within process nominals: Evidence from adverbs and the VP anaphor do-so. Natural Language and Linguistic Theory 19.549-82.

Givón, Talmy. 1991. Serial verbs and the mental reality of 'event.' Approaches to grammaticalization, vol. 1, ed. by Elizabeth C. Traugott and Bernd Heine, 81-127. Amsterdam: John Benjamins.

GoldBerg, Adele. 1995. Constructions: A construction grammar approach to argument structure. Chicago: University of Chicago Press.

Goldberg, Adele, and Ray Jackendoff. 2004. The English resultative as a family of constructions. Language 80.532-68.

GoOD, JeFF C. 2003. Strong linearity: Three case studies towards a theory of morphosyntactic templatic constructions. Berkeley: University of California, Berkeley dissertation.

Grace, George. 1981. An essay on language. Columbia, SC: Hornbeam Press.

Grace, GeORge. 1987. The linguistic construction of reality. London: Croom Helm.

Grice, H. PAul. 1989. Studies in the way of words. Cambridge, MA: Harvard University Press.

Grimshaw, Jane. 1990. Argument structure. Cambridge, MA: MIT Press.

HASEGAWA, Yoko. 1996. A study of Japanese clause linkage: The connective TE in Japanese. Stanford, CA: CSLI Publications.

IbarRetXe-Antuñano, Iraide. 2004a. Dicotomías frente a continuos en la lexicalización de los eventos de movimiento [Dichotomies vs. continua in the lexicalization of motion events]. Revista Española de Lingüística 34.481-510.

IBARRETXE-ANTUÑANO, IRAIDE. 2004b. Language typologies in our language use: The case of Basque motion events in adult oral narratives. Cognitive Linguistics 15.317-49.

IBARRETXe-AntuÑANO, IRAIDE. 2007a. Basque: Going beyond verb-framed typology. Linguistic Typology, to appear. 
IbARRETXE-AntuÑANo, IrAide. 2007b. Lexicalization patterns and sound symbolism in Basque. Zaragoza: University of Zaragoza, MS.

JACKendoff, RAy. 1983. Semantics and cognition. Cambridge, MA: MIT Press.

JACKENDOFF, RAY. 1990. Semantic structures. Cambridge, MA: MIT Press.

JACKENDOFF, RAY. 1997. The architecture of the language faculty. Cambridge, MA: MIT Press.

JACKENDOFF, RAY. 2002. Foundations of language: Brain, meaning, grammar, evolution. New York: Oxford University Press.

KLein, Wolfgang. 1994. Time in language. London: Routledge.

KrifKA, MANFRED. 1998. The origins of telicity. Events and grammar, ed. by Susan Rothstein, 197-235. Dordrecht: Kluwer.

LANDMAN, Fred. 2000. Events and plurality. Dordrecht: Kluwer.

LANGaCKer, Ronald W. 1987. Foundations of cognitive grammer. Stanford, CA: Stanford University Press.

Levelt, Willem J. M. 1989. Speaking. Cambridge, MA: MIT Press.

LeVI, Judith. 1978. The syntax and semantics of complex nominals. New York: Academic Press.

Levinson, StePhen C. 1987. Pragmatics and the grammar of anaphora: A partial pragmatic reduction of binding and control phenomena. Journal of Linguistics 23.379-434.

Levinson, StePhen C. 1996. Frames of reference and Molyneux's question. Language and space, ed. by Paul Bloom, Mary A. Peterson, Lynn Nadel, and Merrill F. Garrett, 109-69. Cambridge, MA: MIT Press.

Levinson, STEPHEN C. 1997. From outer to inner space: Linguistic categories and nonlinguistic thinking. With language in mind: The relationship between linguistic and conceptual representation, ed. by Eric Pederson and Jan Nuyts, 13-45. Cambridge: Cambridge University Press.

Levinson, StePhen C. 2006. The language of space in Yélî Dnye. In Levinson \& Wilkins, $157-205$.

Levinson, Stephen C.; Sérgio Meira; and the Language and Cognition Group. 2003. 'Natural concepts' in the spatial topological domain-adpositional meanings in crosslinguistic perspective: An exercise in semantic typology. Language 79.485-516.

Levinson, Stephen C., and David P. Wilkins (eds.) 2006. Grammars of space. Cambridge: Cambridge University Press.

Lounsbury, Floyd G. 1969. Crow- and Omaha-type kinship terminologies. Cognitive anthropology, ed. by Stephen A. Tyler, 212-55. New York: Holt, Rinehart, and Winston.

LÜPKE, FRIEDERIKE. 2005. A grammar of Jalonke argument structure. Nijmegen: Radboud University Nijmegen dissertation.

Margetts, Anna. 2004. Core-layer serialization in Saliba. Complex verbs and serialization in Oceanic languages, ed. by Isabelle Brill and Françoise Ozanne-Rivierre, 69-89. Berlin: Mouton de Gruyter.

Mатsumoto, Yo. 1996. Complex predicates in Japanese: A syntactic and semantic study of the notion 'word'. Stanford, CA: CSLI Publications.

MCCAWLEY, JAMES. 1988. The syntactic phenomena of English, vol. 2. Chicago: University of Chicago Press.

Miller, George A., and Philip N. Johnson-Laird. 1976. Language and perception. Cambridge: Cambridge University Press.

Muehleisen, Victoria, and Mutsumi Imai. 1996. Transitivity and the incorporation of ground information in Japanese path verbs. Lexical and syntactical constructions and the construction of meaning, ed. by Marjolijn H. Verspoor, Kee Dong Lee, and Eve Sweetser, 329-46. Amsterdam: John Benjamins.

Narasimhan, Bhuvana. 2003. Motion events and the lexicon: The case of Hindi. Lingua 113.2.123-60.

NewtSon, DARREL. 1973. Attribution and the unit of perception of ongoing behavior. Journal of Personality and Social Psychology 28.1.28-38.

NikanNe, Urpo. 1990. Zones and tiers: A study of thematic structure. Helsinki: Finnish Literature Society.

Nikitina, Tatiana. 2006. Subcategorization pattern and lexical meaning of motion verbs: A study of the source/goal ambiguity. Stanford, CA: Stanford University, MS.

Nunes, Mary L. 1993. Argument linking in English derived nominals. Advances in role and reference grammar, ed. by Robert Van Valin, Jr., 375-432. Amsterdam: John Benjamins. 
Osam, E. Kweku. 1994. Aspects of Akan grammar: A functionalist perspective. Eugene: University of Oregon dissertation.

Parsons, Terrence. 1990. Events in the semantics of English. Cambridge, MA: MIT Press.

PAWLEY, ANDREW. 1987. Encoding events in Kalam and English: Different logics for reporting experience. Coherence and grounding in discourse, ed. by Russell S. Tomlin, 329-60. Amsterdam: John Benjamins.

Pederson, Eric; Eve Danziger; David P. Wilkins; Stephen C. Levinson; Sotaro Kita; and Gunter SenFt. 1998. Semantic typology and spatial conceptualization. Language 74.557-89.

Pianesi, Fabio, and Achille C. Varzi. 2000. Events and event talk: An introduction. Speaking of events, ed. by James Higginbotham, Fabio Pianesi, and Achille C. Varzi, 3-47. New York: Oxford University Press.

Pinker, Stephen. 1989. Learnability and cognition. Cambridge, MA: MIT Press.

Rappaport Hovav, Malka, and Beth Levin. 2001. An event structure account of English resultatives. Language 77.766-97.

Reinhart, TANyA. 1983. Anaphora and semantic interpretation. Chicago: University of Chicago Press.

SAPIR, EdWARD. 1931. Conceptual categories in primitive languages. Science 74.578.

SCHILlER, ERIC. 1989. On the phrase structure of serial verb constructions. Chicago Linguistic Society 25.404-19.

Sebba, Mark. 1987. The syntax of serial verbs. Amsterdam: John Benjamins.

SENFT, GunTER. 1999. ENTER and EXIT in Kilivila. Studies in Language 23.1-23.

TAI, JAMES H.-Y. 1985. Temporal sequence and Chinese word order. Iconicity in syntax, ed. by John Haiman, 49-72. Amsterdam: John Benjamins.

TALMY, LEONARD. 1985. Lexicalization patterns. Language typology and syntactic description, vol. 3: Grammatical categories and the lexicon, ed. by Timothy Shopen, 57-149. Cambridge: Cambridge University Press.

TAlmy, LeONARD. 1991. Path to realization: A typology of event conflation. Berkeley Linguistics Society 17.480-519.

TALmy, LeONARD. 2000. Towards a cognitive semantics. Cambridge, MA: MIT Press.

van DER Zee, Emile. 2000. Curvature representation in the lexical interface. Cognitive interfaces: Constraints on linking cognitive information, ed. by Emile van der Zee and Urpo Nikanne, 143-82. Oxford: Oxford University Press.

van Staden, Miriam, and Ger ReEsink. 2008. Serial verb constructions in a linguistic area. Serial verb constructions in Austronesian and Papuan languages, ed. by Gunter Senft. Canberra: Pacific Linguistics, to appear.

van Staden, Miriam; Gunter Senft; Nicholas J. Enfield; and Jürgen Bohnemeyer. 2001. Staged events. 'Manual' for the field season 2001, ed. by Nicholas J. Enfield, 115-25. Nijmegen: Max Planck Institute for Psycholinguistics.

WierzBicka, AnNa. 1980. Lingua mentalis. Sydney: Academic Press.

Wilkins, David P. 2004. The verbalization of motion events in Arrernte. Relating events in narrative: Typologiocal and contextual perspectives, ed. by Sven Strømqvist and Ludo Verhoeven, 143-57. Mahwah, NJ: Lawrence Erlbaum.

ZACKS, JEFF, and BARBARA TVERSKy. 2001. Event structure in perception and conception. Psychological Bulletin 127.3-21.

Zlatev, Jordan, and Peerapat Yangklang. 2004. A third way to travel: The place of Thai in motion event typology. Relating events in narrative: Typological and contextual perspectives, ed. by Sven Strømqvist and Ludo Verhoeven, 159-90. Mahwah, NJ: Lawrence Erlbaum.

ZuCCHI, Alessandro. 1989. The language of propositions and events: Issues in the syntax and semantics of nominalization. Amherst: University of Massachusetts, Amherst dissertation.

Bohnemeyer

Department of Linguistics

University at Buffalo-SUNY

609 Baldy Hall

Buffalo, NY 14260

[jb77@buffalo.edu]
[Received 30 August 2005; revision invited 22 April 2006; revision received 2 August 2006; accepted 22 December 2006] 